\title{
CABALLOS EN ARCILLA DE LA SEGUNDA EDAD DEL HIERRO EN LA PENÍNSULA IBÉRICA ${ }^{[1]}$
}

\author{
FERNANDO QUESADA SANZ \\ MARTA TORTAJADA RUBio \\ Dpto. de Prehistoria y Arqueología \\ Universidad Autónoma de Madrid
}

\section{Resumen}

Las figuras de caballos y otros équidos realizadas en arcilla son una manifestación modesta pero muy significativa de la importancia de estos animales en la Edad del Hierro peninsular. Se presenta un catálogo detallado, mapas de distribución, análisis de tipos, cronología y dispersión, como parte de un estudio global sobre estos animales.

\section{Summary}

Small clay figures of horses and other equids are a modest but significant expression of the importance of these animals in the Iberian Iron Age. We present a detailed catalogue, distribution maps, typological analysis, chronology and geographical distribution of these figures. All of it forms part of a wider research project on the role of equids in the Iron Age of the Peninsula.

Las representaciones de équidos sobre arcilla constituyen una de las categorías menos vistosas de representaciones de estos animales en la Edad del Hierro peninsular. Sin embargo, por su número, variedad de tipos y dispersión conviene hacer una revisión de conjunto que permita abordar su análisis sistemático.

[1] Trabajo realizado dentro del Proyecto de Investigación 'Modelos de jerarquización social en la Protohistoria de la Península Ibérica: los ritos de armas y caballos como estudio de caso'. PB97/0057. 
El catálogo que aquí presentamos abarca dos grandes zonas de la Iberia prerromana: el mundo ibérico en sentido amplio (Andalucía, Sureste, Levante, cuenca baja del Ebro y Cataluña) y grandes regiones del interior peninsular que incluyen lo que en sentido amplio se viene llamando 'mundo celtibérico' ${ }^{[2]}$ (cuencas media y alta del Duero y del Tajo, cuenca alta del Júcar). Aunque inicialmente nuestra indagación se centraba en el ámbito 'ibérico', la evidencia de que muchos tipos son comunes en ambas regiones ${ }^{[3]}$ nos ha llevado a incluir ambas, como por otra parte han tenido que hacer otros estudiosos en artículos anteriores (e.g. Galán Domingo, 1989:90; Maluquer, 1963). No se tienen en cuenta en este estudio amplias regiones en las que también se conocen équidos en arcilla, como Extremadura o sur de Portugal.

No nos hacemos ilusiones sobre el grado de exhaustividad de nuestro catálogo. Aunque hemos procurado hacer una búsqueda lo más sistemática posible, en museos y colecciones tanto como en bibliotecas, somos conscientes de que la gran extensión del área abarcada dificulta una catalogación completa, y de que el carácter 'menor' de este tipo de hallazgos hace que probablemente piezas del tipo que estudiamos duerman todavía, inéditas, en museos y colecciones. Pese a ello, estamos convencidos de que la búsqueda ha sido lo suficientemente intensa e intensiva como para que el centenar de piezas que recogemos sea una muestra representativa tanto de los tipos de objetos como de la densidad de hallazgos y dispersión de los mismos. Por tanto, creemos que este corpus resulta ser la mejor base de datos hasta ahora disponible para realizar una aproximación bien orientada al estudio detallado de estos objetos, que han sido objeto sólo de algunos análisis parciales por regiones o por tipos, normalmente mezclados con otras figuras zoomorfas (e.g. Alonso, Benito, 1992; Balil, 1956; Galán, 1989-90; Genera, 1988; Hernández, Gil, 1999; Maluquer, 1963; Martín Valls, 1990; Otiña, 1999; Sánchez Moreno, 1995-96; Vilá, 1994, etc.; sobre todo destacamos el reciente trabajo de F. Blanco sobre los équidos en la Meseta, Blanco 2001).

Hemos recogido todas las categorías de representación de équidos en arcilla en tres dimensiones o en relieve, normalmente cocidas intencionalmente, aunque en algún caso (Cerrón de Illescas, $\mathrm{n}^{\circ} 28$ ) la cocción haya sido accidental. Somos de entrada conscientes de que el criterio de agrupación empleado en este trabajo (la materia prima) es discutible, porque incluye tipos muy diferentes (posibles exvotos, apliques sobre recipientes, relieves, etc.). Desde luego, sería posible emplear otro criterio y agrupar las pequeñas figurillas con los exvotos de bronce, los relieves con los relieves de piedra, etc. Sin embargo, no pedimos excusas por la elección realizada: este estudio se integra en un proyecto mucho mayor ${ }^{[4]}$, donde alcanza su pleno contenido; pero además, la modestia de la materia prima

[2] Abarcando zonas no 'celtibéricas' en sentido estricto, del mismo modo que se viene haciendo en los sucesivos congresos dirigidos por $\mathrm{F}$. Burillo Mozota sobre el mundo celtibérico, y que abarcan, además de la Celtiberia en sentido estricto, el curso medio del Duero y el ámbito abulense (zonas vaccea y vetona) y la cuenca alta del Júcar.

[3] Al igual que ocurre con otros elementos asociados al caballo, como son los arreos, que no pueden estudiarse separadamente.

[4] Ver nota 1. 
(barro) hace que todos los objetos aquí recogidos se aparten de los objetos, quizá similares, realizados en materiales mucho más nobles como piedra, bronce o incluso metales preciosos. En consecuencia, su análisis conjunto tiene también pleno sentido.

No pretendemos hacer aquí un estudio detallado de todas las facetas (cronología, análisis contextual, significado conjunto y de cada tipo de objetos), labor casi propia de una monografía, sino recoger la información conjuntamente para poder observarla en mejor perspectiva, y compararla con otras imágenes de équidos en diferentes soportes. No se espere pues aquí un análisis exhaustivo sobre la presencia de cabezas de caballo en los exvotos en forma de planta de pie de Numancia, o sobre los cazos. Algunos trabajos de detalle se han realizado ya con gran competencia, mientras que otros exigen probablemente una perspectiva global previa como la que aquí tratamos de presentar.

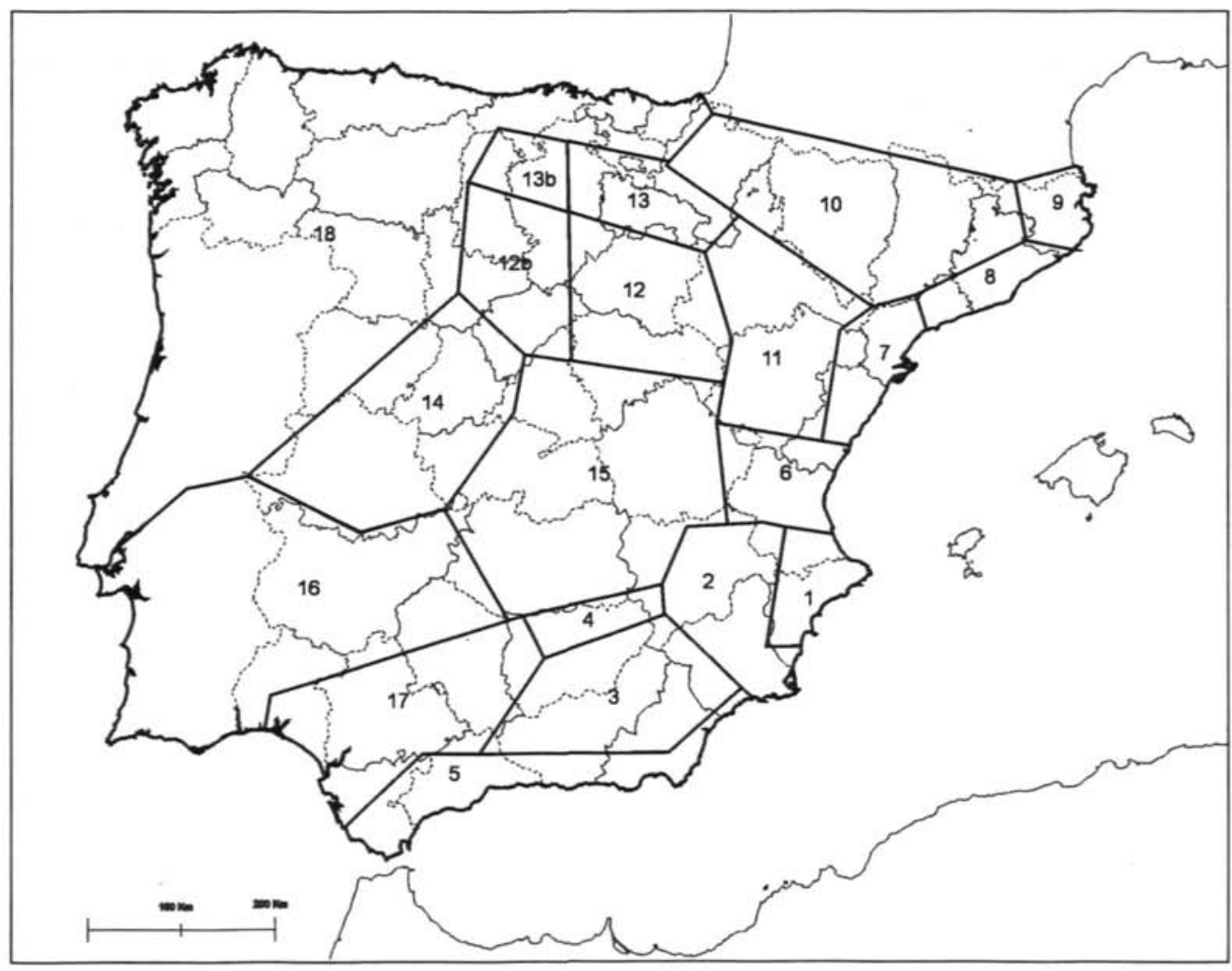

Figura 1: Regiones utilizadas en la elaboración del Catálogo. Para una explicación más detallada de su lógica, ver Quesada (1997:31 ss.). 


\section{CATÁLOGO DE PIEZAS}

(por orden alfabético de yacimiento)

Número de catálogo (subrayado si la pieza es muy dudosa).

Yacimiento. Número de Yacimiento. Provincia. Región. Típo de objeto.

Descripción y observaciones.

Dimensiones (en cm., altura $x$ longitud $x$ fondo). Conservación $(E=e x c e l e n t e ; B:=b u e n a ; ~ R$ : regular; $M=$ mala; $D$ : casi destruido).

Cronología del yacimiento y del contexto en su caso.

Bibliografia.

\section{Cat. 1}

LA ABEJUELA (1111). Teruel, reg. 6. TERRACOTA (BULTO R.). Figurilla exenta.

Figura muy estilizada y erosionada. Barro. Sólo una foto. R.

Sin datos. Sin datos.

MARCO SIMÓN 1989:124. GALÁN DOMINGO 1989-90:185.

\section{Cat. 2}

AGUILAR DE ANGUITA (267) Guadalajara, reg. 12. TERRACOTA (BULTO R.). Figurilla en tapadera. Sepultura 'P'. Asidero de tapadera con forma de caballo. Completa. Representación equina modelada sirviendo de asidero a una tapadera plana circular. Según Cerralbo, unos orificios practicados en la tapadera junto al caballo podrían haber pertenecido a un hipotético jinete. Arcilla modelada y cocida. Según A. Lorrio (1994, MM35), la tumba sería de su fase IIA, fechada en el s. V a.C. por armas de frontón y urna de orejetas de tipo ibérico.

E.

ss. V-I a.C.; ¿s. V a.C. ?.

AGUILERA Y GAMBOA 1911 (III): lám CXXXIV, 1 y 2. CABRÉ DE MORÁN 1990: fig. 10, izq. LORRIO 1997:243. BLANCO GARCÍA 2001 (e.p): 110, fig. 4,1.

\section{Cat. 3}

LAS ARRIBILLAS (CERRO REDONDO) (1095). Guadalajara, reg. 12. TERRACOTA (BULTO R.).

Figura exenta.

Campaña de 1987-88, interior de vivienda, al nivel del pavimento. Figura de caballo al que le faltan las patas y parte de la cola. Se señalan superficialmente las orejas, boca, crines y costillas. Sin montura. Sin pintar. Modelada y cocida en arcilla, desgastada, cocción reductora. Posible exvoto o juguete. Similar a los de Numancia. Asociada a otras dos terracotas de équido, una femenina y un jabalí. Quemada por el incendio de la vivienda donde se encontró.

3,7x7,3. R.

s. I a.C.

GALÁN DOMINGO 1989-90:181, fig. 3.2 y 181-182, fig. 4.1. LORRIO 1997: Fig. 102.2. BLANCO GARCÍA 2001(e.p):113, fig.5,3.

\section{Cat. 4}

LAS ARRIBILLAS (CERRO REDONDO) (1095). Guadalajara, reg. 12. TERRACOTA (BULTO R.). Figura exenta.

Campaña de 1987-88, interior de vivienda, al nivel del pavimento. Cuartos traseros de cuadrúpedo, posible caballo por similitud con otro ejemplar, aunque quizá bóvido. Se conserva parte del arranque de la pata trasera. Modelado y cocido en arcilla, muy desgastada. Pasta reducida. Exvoto o juguete. 
Similar a Numancia. Rotura antigua. Asociada a otras dos terracotas de équido, una femenina y un jabalí. Quemada por el incendio de la vivienda.

$3,2 \times 3,8 . M$.

GALÁN DOMINGO 1989-90:181, fig.3.2 y 181-182, fig.4.1. LORRIO 1997: Fig. 102.5. BLANCO GARCÍA 2001 (e.p): 113, fig. 5,4.

\section{Cat. 5}

LAS ARRIBILLAS (CERRO REDONDO) (1095). Guadalajara, reg. 12. TERRACOTA (BULTO R.). Figura exenta.

Campaña de 1987-88, interior de vivienda, al nivel del pavimento. Fragmento de cabeza de équido, casi irreconocible. Hocico saliente y oreja puntiaguda. Perforación longitudinal de $0,6 \mathrm{~cm}$. de diámetro. Con rápidas incisiones se trazaron boca y ollares. Diferente de las otras dos piezas del yacimiento. Arcilla modelada y cocida. Reducida. Exvoto o juguete. Asociada a otras dos terracotas de équido, una femenina y un jabalí. Quemada por el incendio de la vivienda.

$4,1 \times 5,1$. M.

GALÁN DOMINGO 1989-90:182, fig. 42. BLANCO GARCÍA 2001 (e.p): fig. 5,12.

\section{Cat. 6}

BAZA (42) Granada, reg. 3. TERRACOTA (BULTO R.). Figura exenta (?).

Hallazgo Tumba 27, año 1969. Cabeza de caballo de cerámica gris y pintura roja. Falta el cuerpo. Se ha representado la cabezada aunque no el freno, el ojo, y las orejas pronunciadas. Barro cocido gris con pintura roja postcocción y decorada. Material enviado por orden de la Comisaría General al MAN donde se dibujaron, restauraron y fotografiaron a costa de Durán Farrell. Pero la pieza no se recoge en la monografía de M.J. Conde (1992). Las dimensiones se dan a partir de la escala gráfica de 1 dibujo. El texto da una $\mathrm{lg}$. de $2,8 \mathrm{~cm}$. Uriarte (2001) indica erróneamente que es de piedra.

$5,17 \times 6 . \mathrm{R}$.

s. IV a.C.; s. IV a.C.

PRESEDO VELO 1982:55, fig . 27, 23. URIARTE 2001:144 .

\section{Cat. 7}

LA BORRACHA (1103). Murcia, reg. 2. TERRACOTA (BULTO R.). Figura exenta.

Superficie. Fragmento de cuadrúpedo, posiblemente caballo. Se conservan los cuartos delanteros, el arranque y parte de las patas delanteras, todo el cuello y parte superior de la cabeza. Arcilla cocida. Pasta depurada de color beige claro. Asociada a terracotas femeninas y materiales hispanorromanos. $4,9 \times 3,7 . \mathrm{M}$.

Hispanorromano. ¿altoimperial?.

HERNÁNDEZ CARRIÓN, GIL GONZÁLEZ 1999:367-374. Lám.1, BOT-0006.

\section{Cat. $\underline{8}$}

LA BORRACHA (1103). Murcia, reg. 2. TERRACOTA (BULTO R.). Figura exenta.

Superficie. Caballo al que le falta cabeza y cuello, patas delanteras y final de traseras y parte de la cola.

Montura - ¿manta o silla?- redondeada en relieve, incisiones en cuello y crines. Arcilla cocida. Pasta depurada, al interior núcleo gris y el resto color rosáceo, al exterior amarillo. Asociadas a terracotas femeninas y materiales hispanorromanos.

$5,6 \times 3,65$. R.

Sin datos. Hispanorromano. ¿altoimperial?.

HERNÁNDEZ CARRIÓN, GIL GONZÁLEZ 1999:367-374. Lám.1, BO-T-0008. 


\section{Cat. 9}

CABECICO DEL TESORO (49). Murcia, reg. 2. TERRACOTA (BULTO R.). Figura exenta.

Équido indeterminado casi completo, salvo una pata. Tosco. Sin arreos.

La acémila no lleva arreos. Sobre el lomo, a ambos lados, dos grandes toneles con cuello, del tipo conocido en la cerámica ibérica.

Arcilla cocida sin pintar. Restos de quemado.

$8 \times 17$. B.

Fin s. V a.C.-mediados s. I a.C. Sin datos.

QUESADA (2000:85)

\section{Cat. 10}

CABEZO DE LA GUARDIA (ALCORISA) (1010). Teruel, reg. 11. TERRACOTA (BULTO R.). Figura exenta.

GALÁN DOMINGO 1989-90:184.

\section{Cat. 11}

CAMINO DEL PEDREGAL (1092). Murcia, reg. 2. TERRACOTA (BULTO R.). Figura exenta.

Excavación de 1992. Estrato superficial. UE 21.000A. Pequeña cabeza de caballo 'con tupé muy marcado'. (QQuizá ovino?). Ojos en forma almendrada y cuello con ondulaciones. Crines muy marcadas. Aspecto ovejuno. Cerámica cocida a molde, pasta depurada de color amarillo. El yacimiento (¿una villa?) se abandonó a principios del s. III d.C. Cronología debatible. Asociado a terracotas femeninas. $2,34 \times 2,08$. M.

Romano. Imperial?.

HERNÁNDEZ CARRIÓN, GIL GONZÁLEZ 1999:367-374, Lám.1, CP-T-0002.

\section{Cat. 12}

CAN BUTINYA (1093). Barcelona, reg. 8. TERRACOTA (BULTO R.). Figura exenta.

Encontrada superficialmente en un terreno formado por arcillas del cuaternario junto a la masía. Fragmento de animal, posible caballo, conserva el torso del animal y oreja, parte de montura y arranque pata delantera. Se aprecia un orificio en el lugar del ojo. Parece más una silla que una manta. Arcilla modelada a mano marrón claro y desengrasantes de mica depurada y fina. Contexto romanorepublicano.

$7,1 \times 8 . \mathrm{M}$.

s. III a.C.-meds. II d.C. ; ¿s. II-I a.C?

DE LA PINTA:1983:161-167, fig. 2,1. VILÁ 1994:147. OLLE, OTIN̂A, VALVERDU 1997-98:27-40. OTIÑA 1999.

\section{Cat. 13}

CAN BUTINYA (1093). Barcelona, reg. 8. TERRACOTA (BULTO R.). Figura exenta.

Encontrada superficialmente en un terreno formado por arcillas del cuaternario junto a la masía. Fragmento de caballo que conserva la parte baja posterior de la montura. Destaca parte de la montura y cola. Arcilla modelada a mano marrón claro y desengrasantes de mica depurada y fina. Contexto romano-republicano.

$2,3 \times 4,4 . M$.

s. III a.C.-meds. II d.C.; ¿s. II-I a.C. ? M.

DE LA PINTA:1983:161-167, fig. 2,2. OTIÑA 1999. OLLE, OTIÑA, VALVERDU 1997-98:27-40.VILÁ 1994:147.

\section{Cat. 14}

CAN BUTINYA (1093). Barcelona, reg. 8. TERRACOTA (BULTO R.). Figura exenta.

Encontrada superficialmente en un terreno formado por arcillas del cuaternario junto a la masía. 
Fragmento de cuartos traseros de animal, posible caballo. Destaca parte de la montura y cola. Arcilla modelada a mano marrón claro y desengrasantes de mica depurada y fina. Contexto romano-republicano.

$1,9 \times 4,6 . \mathrm{M}$.

s. III a.C.-meds. II d.C.; ¿s. II-I a.C. ?.

DE LA PINTA:1983:161-167, fig. 2,3.VILÁ 1994:147. OLLE, OTIÑA, VALVERDU 1997-98: 27-40. OTIÑA 1999.

\section{Cat. 15}

CAN BUTINYA (1093). Barcelona, reg. 8. TERRACOTA (BULTO R.). Figura exenta.

Sin contexto arqueológico. Fragmento del cuerpo de un cuadrúpedo. ¿caballo?. Sin cabeza, ni patas ni cola. Incisiones en el lomo. Factura tosca y pasta marrón oscura, dura y cuidada. Forma parte de un conjunto.

$3,2 \times 6,4 . M$.

s. III a.C.-meds. II d.C.; ¿s. II-I a.C. ?.

DE LA PINTA 1983:161-167, fig.3,1. VILÁ 1994:144 y Fig. 6d.

\section{Cat. 16}

CAN BUTINYA (1093) Barcelona, reg. 8. TERRACOTA (BULTO R.). Figura exenta.

Sin contexto arqueológico. Fragmento de animal sin cabeza, patas ni gran parte de la cola. Sólo queda parte del lomo y cola. Arcilla marrón y naranja y desgrasante de mica.

$1,7 \times 3,7$. D.

s. III a.C.-meds. II d.C.; ¿s. II-I a.C.?

DE LA PINTA:1983:161-167, fig. 3,2. VILÁ 1994:141-149.

\section{Cat. 17}

CAN BUTINYA (1093) Barcelona, reg. 8. TERRACOTA (BULTO R.). Figura exenta.

Sin contexto arqueológico. Fragmento del cuerpo de una animal con arranque de cuello y pata. Arcilla gris marrón por efecto de la cocción y desengrasantes de mica negros y cuarzo.

$2,03 \times 4,4$. D.

s. III a.C.-meds. II d.C.; ¿ss. II-I a.C. ?.

DE LA PINTA: 1983:161-167, fig.3,3. VILÁ 1994:141-149.

\section{Cat. 18}

CAN VEDELL (1094). Barcelona, reg. 8. TERRACOTA (BULTO R.). Figura exenta.

Can Vedell (Bigues-Riells del Fai). Silo número 2. Cabeza y cuello de caballo con orificio que lo atraviesa desde la boca a la base del cuello. Especie de pequeña parrilla decorativa en el cuello. Cronología por los materiales del silo al que se asocia.

$3,2 \times 5,1 . \mathrm{M}$.

ss. III-II a.C.

HERNÁNDEZ YLLÁN:1983:63, fig. 2. VILÁ 1994:141-149.

\section{Cat. 19}

CARRAPOSA (110). Valencia, reg. 1. TERRACOTA (BULTO R.). Figuras exentas.

Valle del río Canyoles. En el extremo sur de la cima, en superficie de $300 \mathrm{~m} 2$ en un poblado de 2 Ha. Pequeñas terracotas de équidos y algún bóvido (X 20). Sin foto ni descripción. Aparecieron junto a cerámica ibérica, 20 terracotas de équidos y bóvidos. Material en superficie muy meteorizado. Ánforas itálicas campanas. ¿¿Santuario? ¿depósito votivo?.

M.

Tardío.

PÉREZ BALLESTER, BORREDA MEJIAS 1998:133-152. 


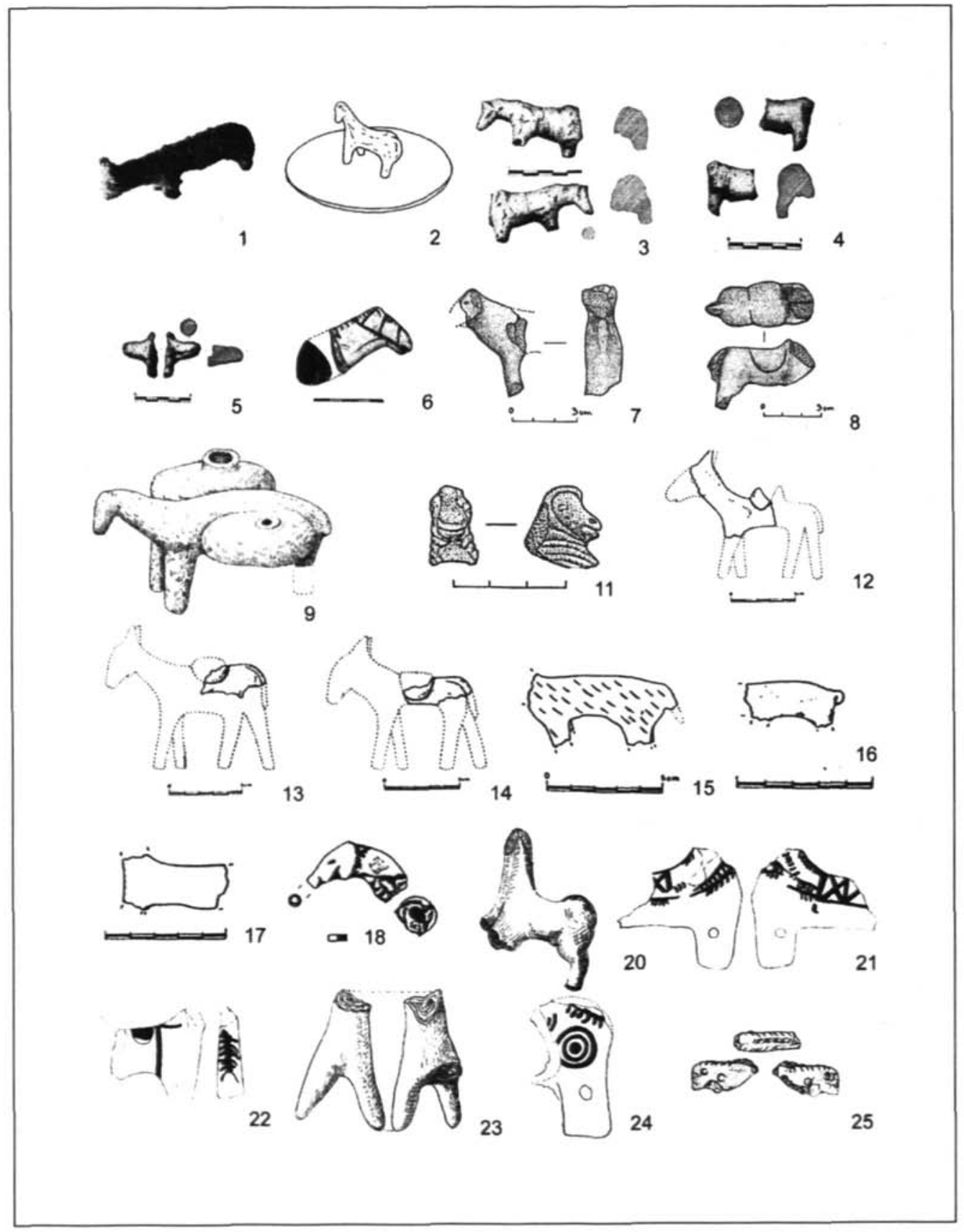

Lamina I. Terracotas de équidos en la Edad del Hierro. 


\section{Cat. 20}

EL CASTELILLO DE ALLOZA (218). Teruel, reg. 11. TERRACOTA (BULTO R.) Figura exenta.

4-5 campañas de excavación, Habitación 8. Caballito. Modelado tosco. Falta la cabeza y tres patas. Sin montura ni arreos pintados o incisos. Barro buena calidad rojizo sin impurezas. Restos de incendio en la habitación, común a todo el poblado. Marco Simón lo considera un exvoto.

$8,5 \times 6 . R$.

ss. VI-II a.C.; II a.C.

ATRIÁN 1966: 186, y Fig. 31 y Lám. XI.2. MARCO SIMÓN 1984:91. GALÁN DOMINGO 1989-90:184.

\section{Cat. 21}

EL CASTELILLO DE ALLOZA (218). Teruel, reg. 11. TERRACOTA (BULTO R.). ¿Morillo?.

4-5 campañas de excavación, Habitación 8. Morillo. Manos de cuadrúpedo (¿équido?). Orificio en la parte inferior de la mano. Se representan con pintura la manta de montar, crines y quizá petral, con esquematización geométrica. Pasta siena anaranjada de tono vivo bien tamizada. Repasado con espátula. Pintura achocolatada. Restos de incendio en la habitación, común a todo el poblado.

$11,5 \mathrm{x}$ ?. R.

ss. VI-II a.C.; II o II-I a.C.

ATRIÁN 1966:185 y Fig. 30.2.GALÁN DOMINGO 1989-90:184.

\section{Cat. 22}

EL CASTELILLO DE ALLOZA (218). Teruel, reg. 11. TERRACOTA (BULTO R.). Morillo.

4-5 campañas de excavación, Habitación 8. Morillo en forma de équido. Perforado en la pata del animal. Con pintura se señala la manta de montar, cincha y rienda o baticola (?), y quizá la cola si se trata de los cuartos traseros. Pasta siena gris maciza y compacta. Retocado con espátula al exterior. Pintura quemada, de tono gris. Restos de incendio en la habitación, común a todo el poblado.

10. $\mathrm{R}$.

ss. VI-II a.C.; II o II-I a.C.

ATRIÁN 1966:184-5 y Fig. 30.1.GALÁN DOMINGO 1989-90:184.

\section{Cat. 23}

EL CASTELILLO DE ALLOZA (218). Teruel, reg. 11. TERRACOTA (BULTO R.). Figura exenta.

Segunda y tercera campaña. Habitación 4. Cuadrúpedo fragmentado. Sin decorar. Arcilla (sin más detalles). Asociada a Campaniense A, F. 27L.

R

ss. VI-II a.C.; s. II-I a.C.

ATRIÁN 1959:243 y Fig. 16. GALÁN DOMINGO 1989-90:184.

\section{Cat. 24}

EL CASTELILLO DE ALLOZA (218). Teruel, reg. 11. TERRACOTA (BULTO R.). Morillo.

Campañas 4-5. Habitación 7. Fragmento de morillo con orificio en la parte inferior. Podrían ser los cuartos traseros de un cuadrúpedo (jéquido?). Decorado con pintura. Barro cocido con pasta de extraordinaria calidad, fina y tamizada. Quizá de la destrucción tardía del poblado.

$10 \mathrm{x}$ ?. M.

ss. VI-II a.C. Sin datos.

ATRIÁN 1966:163 y Fig. 9.GALÁN DOMINGO 1989-90:184.

\section{Cat. 25}

CERRO DE LA VIRGEN DE TORMEJÓN (1095). Segovia, reg. 12b. TERRACOTA (BULTO R.). Morillo?. Armuña. Excavación de F. Gozalo en 1977. Fragmento de morillo en forma de équido. (?). Sin cabeza ni patas, solo cuartos traseros y lomo hasta el arranque del cuello (contra Barrio, quien habla de una cabeza esquemática, 1999:108). Se han indicado los crines mediante hileras de incisiones parale- 
las entre si. Arcilla en mal estado, no pintada. Identificación como équido incierta. Cronología probable deducida según paralelos en Cataluña y sur de Francia.

M.

Hierro I-s. I a.C.?; ¿ss. III-II a.C. ?. Para Blanco, quizás s.II a.C.

BARRIO MARTÍN 1994:408 y ss., fig. 3,a; 1999:107 y 246, fig. 69, centro. BLANCO GARCÍA 2001 (e.p): 112 , fig. 4,10.

\section{Cat. 26}

CERRO DE LA VIRGEN DE TORMEJÓN (1095). Segovia, reg. 12b. TERRACOTA (BULTO R.). Figura exenta.

(Armuña) Excavaciones de F.Gozalo en 1977. Hallado en un contexto habitacional. Fragmento de cuartos traseros de cuadrúpedo (¿équido?) de torso muy grueso, masivo. Barro. De cronología imprecisa.

$4,8 \times 6,8 . \mathrm{M}$.

Hierro I - s. I a.C.; ¿ss. III-II a.C. ?.

BARRIO MARTÍN 1994:408 y ss., fig.3,6; Id. 1999: 107 y 246, fig. 69. BLANCO GARCÍA 2001 (e.p): 113, fig. 5,6.

\section{Cat. 27}

CERRO DE LOS SANTOS (76). Albacete, reg. 2. TERRACOTA (BULTO R.). Figura exenta.

Cabeza de caballo de reducidas proporciones. Cabezada de tipo simple, por su forma parece bastante avanzada cronológicamente. Conserva la boca, ojos y resaltada la crin, dividida en mechones por incisiones. Barro cocido modelado. Exvoto. Según Jiménez Navarro, terracota de raigambre técnica púnica. Cuadrado parece dar a entender que es de piedra.

$4 \times 6 . \mathrm{M}$.

ss. IV-I a.C.; Sin datos.

JIMÉNEZ NAVARRO 1943:99-100, Lám. V, 10. CUADRADO 1950: 99-100, Lám. XIII.

\section{Cat. 28}

CERRÓN DE ILLESCAS ( 1024). Toledo, reg. 15. TERRACOTA (RELIEVE).

En el interior de una construcción de un poblado. ¿Lugar de carácter sagrado o simple vivienda?. Relieve realizado en arcilla, formando parte del frente de un banco adosado al muro de una estancia. Cocido por el incendio que destruyó la habitación. Faltan unos $\mathrm{cm}$. de la parte inferior. Procesión que avanza hacia la izqda. En primer lugar (de izqda. a dcha.) una biga tirada por caballos, una figura a pie, otro carro y por último un grifo alado. Modelado en arcilla, pasta de adobe compacta. Cronología basada en material cerámico y estratigrafía. Contexto de santuario probable.

$22 / 30 \times 135$. B.

s. IV-s. II a.C.; ¿c. 210 a.C.?

BALMASEDA Y VALIENTE 1981:215 ss. FERNÁNDEZ MIRANDA Y OLMOS 1986:110-112. VALIENTE 1994 passim, espec. 168-185. ALMAGRO GORBEA, MONEO 2000:59, fig. 26.1.

\section{Cat. 29}

CIGARRALEJO (SANTUARIO) ( 64). Murcia, reg. 2. TERRACOTA (BULTO R.). Figura exenta.

Fuera de contexto. Hallado en la ladera norte, al pie del cantil del santuario. Figurita modelada en barro cocido. Caballo enjaezado fragmentado. La montura es redondeada sin cincha ni petral. Falta parte de la cabeza, grupas y patas. En barro cocido a molde bivalvo. Según Cuadrado, parece un juguete. Al encontrarse en la ladera no se sabe si es exvoto. No hay nada igual in situ. Es tal vez de época posterior a los exvotos.

R.

ss. IV-III a.C.; ?

CUADRADO 1950:229, n 134, Lám. LXXVII. 


\section{Cat. 30}

LOS CIPRESES (1105). Murcia, reg. 2. TERRACOTA (BULTO R.). Figura exenta.

Caballo con tronco, arranques de patas, cuello y cola. Lleva dos incisiones a ambos lados del cuello en su parte inferior y conserva otras dos en un lado en la parte superior del mismo (crines). Tres incisiones en el vientre (¿cinchas o correas?). Un lado arreo o atalaje circular que continúa en cinta que atraviesa el lomo por el centro y discurre hasta cola. Orificio circular en la parte anal. Arcilla cocida. Pasta depurada de color beige anaranjado al exterior y grisácea al interior. Restos de pintura negra y marrón. Procede de la Villa de Jumilla. Asociada a terracotas femeninas.

$5,6 \times 3,13$. R.

med. II-VI d.C.

MOLINA Y MOLINA 1973:84-88. MUÑOZ TOMÁS 1995:112. HERNÁNDEZ CARRION, GIL GONZÁLEZ 1999:367-374. Lám. 1, CI-T-0017.

\section{Cat. 31}

COCA (265). Segovia, reg. 12b. TERRACOTA (BULTO R.). Figura exenta.

Campaña de excavaciones de 1999. Fase IIIe (estrato tardío destruido por arado). Cuartos traseros de animal, posible caballo (dudoso). Le falta la gran parte del cuerpo delantero, y parte de cola y patas. Arcilla modelada y cocida. Material en estrato asociado a construcción vaccea junto a cajita excisa, vasos completos diversos tipos y cerámica gris estampada. De formas típicas numantinas.

M.

VII-I a. C; circa 100 a.C.

PÉREZ GONZÁLEZ, BLANCO GARCÍA 2000:44, fot. inf. arriba.

\section{Cat. 32}

COCA (265). Segovia, reg. 12b. TERRACOTA (BULTO R.). Figura exenta.

Campaña de excavaciones de 1999. Fase IIle. Cuerpo de animal, cuadrúpedo, posible caballo. Solo conserva parte del cuerpo sin extremidades ni cabeza. Arcilla modelada y cocida, deformada y agrietada por la cocción. Material en estrato asociado a construcción vaccea junto a cajita excisa, vasos completos diversos tipos y cerámica gris estampada. De formas típicas numantinas.

D

VII-I a. C.; circa 100 a.C.

PÉREZ GONZÁLEZ Y BLANCO GARCÍA 2000:44, fot. inf. arriba.

\section{Cat. 33}

COCA (265). Segovia, reg. 12b. TERRACOTA (BULTO R.). Figura exenta.

Campaña de excavaciones de 1999. Fase IIIe. Figura de caballo a la que le faltan parte de los cuartos traseros y de las patas delanteras. Sin orejas, no se aprecian rasgos porque está muy desgastado. Arcilla modelada y cocida, deformada y agrietada por la cocción. Material en estrato asociado a construcción vaccea junto a cajita excisa, vasos completos diversos tipos y cerámica gris estampada. De formas típicas numantinas.

R.

VII-Ia.C.; circa 100 a.C.

PÉREZ GONZÁLEZ Y BLANCO GARCÍA 2000:44, fot. inf., abajo izq. BLANCO GARCía 2001(e.p):113, fig. 5,5 .

\section{Cat. 34}

COCA (265). Segovia, reg. 12b. TERRACOTA (BULTO R.). Figura exenta.

Campana de excavaciones de 1999. Figura de caballo sin cabeza ni cuartos traseros. La posición de las patas delanteras parece indicar un équido a galope. Arcilla modelada muy desgastada. Retocada con la ayuda de un cuchillo o navaja. Típico del área vaccea. Apareció junto a cajita excisa, vasos completos diversos tipos y cerámica gris estampada. 
M.

VII-I a.C.; circa 100 a.C.

PÉREZ GONZÁLEZ Y BLANCO GARCÍA 2000:44, fot. inf, arriba dcha. BLANCO GARCÍA 2001(e.p):113, fig. 5,11.

\section{Cat. 35}

LAS COGOTAS (Poblado) (303). Ávila, reg. 14. TERRACOTA (BULTO R.). ¿Figura exenta?

Basurero empleado como testar. Sondeo 1986 por Ruíz Zapatero y UCM, previo a la construcción de una presa. Cuadrícula $\mathrm{n}^{\circ} 10$. Cabeza fragmentada de caballo. Se han representado la boca, los ollares y los ojos marcados por incisiones. Estos últimos se representan con gran detalle. Barro cocido, modelada, cocción oxidante, color marrón-rojiza. Es posible que la pieza fuera un prótomo y hubiera estado adherida a un objeto de mayor tamaño. Cronología determinada por las cerámicas.

$1.9 \times 3,5 . \mathrm{M}$.

ss. V-II a.C.; s. III a.C.

ALONSO Y BENITO 1991-92:525-536. SÁNCHEZ MORENO 1995-96:207-229. BLANCO GARCÍA 2001 e.p:113, fig. 5,8 .

\section{Cat. 36}

LAS COGOTAS (Poblado) (303). Avila, reg. 14. TERRACOTA (BULTO R.). ¿Morillo?

Durante excavaciones en Las Cogotas, Octubre 1990, en contexto de hogares junto a fragmentos de cerámica. Fragmento de morillo. Rematado con el cuello y parte de la cabeza de un caballo. Arcilla en mal estado. Inédito, referencia sólo de ALONSO HERNÁNDEZ Y BENITO LÓPEZ. Se encuentra actualmente en estudio.

ss. V-II a.C.

ALONSO HERNÁNDEZ Y BENITO LÓPEZ 1992:535. BLANCO GARCÍA 2001 (e.p):112.

\section{Cat. 37}

LAS CORTS (AMPURIAS). (178). Gerona, reg. 9. TERRACOTA (BULTO R.). Figura exenta.

Tumba $\mathrm{n}^{\circ} 77$ de incineración, encontrada a $0,58 \mathrm{~m}$ de profundidad. Figurita de caballo con patas y cola fracturadas. Le faltan las patas traseras y la cola, pero mantiene parte de la pata derecha. Orejas puntiagudas y boca marcada. Tierra cocida, gris amarillenta y de factura muy tosca. Según Almagro Basch, significación votiva documentada en Grecia, no es juguete. Parte del ajuar de una tumba junto a cerámica y ungüentario. Contexto romano-republicano.

9,5. M.

ss. II-I a.C.; s. I a.C.

ALMAGRO BASCH 1953:332, fig. 301, 6. BALIL 1956:261.

\section{Cat. 38}

LAS CORTS (AMPURIAS). (178). Gerona, reg. 9. TERRACOTA (BULTO R.). Figura exenta.

Tumba $\mathrm{n}^{\circ} 77$, incineración, encontrada a $0.58 \mathrm{~cm}$ de profundidad. Figurita de caballo con patas y cola fracturadas. Mantiene solo parte de la pata delantera derecha, oreja puntiaguda. Arcilla cocida, gris amarillenta y de factura muy tosca. Significación votiva documentada en Grecia. No juguete. Parte de ajuar de la tumba, junto a cerámica y ungüentario. Contexto romano-republicano.

9,5. R.

ss. II-I a.C.; I a.C.

ALMAGRO BASCH 1953:332, fig. 301, 6. BALIL 1956:261.

\section{Cat. 39}

CUESTA DEL MERCADO (481) Segovia, reg. 12b. TERRACOTA (BULTO R.). FELINO.

Hallazgos casuales, sin excavación. Cabeza de équido muy desgastada, sin orejas. Según Blanco, es un felino, lo que aceptamos. Están señaladas la boca y hocico y los bigotes del felino. Barro anaranjado. 


\section{$3,5 \times 7 . \mathrm{M}$.}

BLANCO GARCÍA 1986:11 como verraco. SÁNCHEZ MORENO 1995-96:215 como caballo. BARRIO MARTÍN, 1994:114, fig. 75, arriba derecha, como felino. BARRIO MARTÍN 1999:114, fig. 75 arriba derecha, como felino. BLANCO 1994: fig.16.14; BLANCO 2001 e.p. 114, como felino.

\section{Cat. 40}

LA FITA (1113). Lérida, Reg. 10. TERRACOTA (BULTO R.). Figura exenta.

Juneda (Les Garrigues). Pieza muy fragmentada. Se conserva la cabeza de un caballo con el ojo perforado y la boca marcada. Bandas de pintura rojo vinosa, marcando los arreos.

GARCÉS 1990:659, fig. 255.4. VILA 1994:142.

\section{Cat. 41}

GARRAFOLS DE VALLMOLL (CAMP DE TARRAGONA) (1099). Tarragona, reg. 8. TERRACOTA (BULTO R.). ¿Figura exenta?

Cerro alrededor del pueblo de Vallmoll, en Els Garrafols. Pata de équido. Muy bien modelada en barro.

M.

s. II-I ? Materiales asociados en superficie incluyen campaniense.

VILASECA DE PALLEJA 1968:362-364, fig. 33. OLLE, OTINิA, VALVERDU 1997-98: 27-40.

\section{Cat. 42}

GASPARES (1035). Almería, reg. 3. TERRACOTA (BULTO R.). ¿Figura exenta ?

En una mancha de humus negro, entre fragmentos de un vaso argárico (sic). Terracota de équido. Caballo al que le faltan los extremos de las patas y punta de las orejas. Lleva una piedrecita en el ojo. Arcilla; realizada aparentemente en molde bivalvo. Pudo llevar peana o haber sido un motivo ornamental de cualquier otro objeto.

$4,2 \times 7,3$. B.

Sin datos. Considerado cuadrúpedo argárico al aparecer entre cerámica realizada a mano. Pero si es molde debería ser hispano romano.

GARCÍA GUIRAO 1977:74-75.

\section{Cat. 43}

GUISSONA (1100). Lérida, reg. 10. TERRACOTA (BULTO R.). Figura exenta.

1934 excavaciones del Servicio de Investigaciones arqueológicas de la Diputación de Barcelona. Contexto de necrópolis, silos ubicados sobre parte del poblado abandonado, extramuros de la ciudad, en la plaza llamada de Vall de Pla. Cabeza de équido, cuello y parte del arranque del torso. Faltan orejas y parte del bocado. La cabezada se representa con una tirilla de arcilla, decorada con discos, al igual que para los ojos, le falta uno. En posición de avance. Arcilla cocida, compacta y buena cocción, con engobe rosáceo. En relieve, crin, bridas y petral con pintura roja. Martín Tobías discute que los silos sean necrópolis.

9. M.

IV-II a.C. Fin II-I a.C. Según GARCÉS son del I a.C. por el engobe rosáceo típico de esa época. Apareció junto a vasos helenísticos (Campaniense B F. 3 y 10) y lamparillas de la misma época ¿silo?. Vilá les da una fecha muy antigua, del IV-III a.C.

COLOMINAS 1941: 35-38 y Lám. V. BALIL 1956:254. MARTIN TOBÍAS 1960-61: 194-196. MALUQUER 1969. GENERA 1988:225. GARCÉS 1991: 802. VILÁ 1994: 142.

\section{Cat. 44}

GUISSONA (1100). Lérida, reg. 10. TERRACOTA (BULTO R.). Figura exenta.

1934 excavaciones del Servicio de Investigaciones arqueológicas de la Diput. Barcelona. Contexto de necrópolis, silos ubicados sobre parte del poblado abandonado, extramuros de la ciudad, en la plaza 
llamada de Vall de Pla. Cabeza de équido, orejas rotas. Faltan patas. Representación de ojos mediante la aplicación de discos de arcilla, hocico adelantado, patas en actitud de correr. Dibujado el pelaje y bocado con pintura roja. Arcilla cocida, buena cocción, con engobe rosáceo. Decorado con pintura roja. Según MARTÍN TOBÍAS y VILÁ, es un bóvido, cabrita. Martín Tobías discute que los silos sean necrópolis.

7. $M$.

IV-II a.C.; fin II-I a.C. Según GARCÉS son del I a.C. por el engobe rosáceo típico de esa época (además, hay asociación a Campaniense B, f. 3 y 10) Según Genera, es caballito. Vilá les da una fecha muy antigua, del IV-III a.C.

COLOMINAS 1941: 35-38 y Lám. V. BALIL 1956:254. MARTIN TOBÍAS 1960-61: 194-196. MALUQUER 1969. GENERA 1988:225. GARCÉS 1991: 802. VILÁ 1994: 142.

\section{Cat. 45}

JEBUT (1102). Lérida, reg. 10. TERRACOTA (BULTO R.). Caballo con jinete.

Sin foto, sólo hay referencias aisladas. 'Rústico' según Martín Tobías.

Sin datos.

Sin datos.

MARTÍN TOBÍAS 1960-61: 295. VILA 1994:142.

\section{Cat. 46}

LANGA DE DUERO (296). Soria, reg. 12. TERRACOTA (BULTO R.). Figura exenta.

Segortia Lanca-Las Quintanas. Figura de équido, fragmentada patas, cabeza y cola. Sin decorar. No hay arreos. Modelada en arcilla rojiza, cocida y pulimentada. 'Exvotos' según Taracena Aguirre.

M.

Celtibérica./Imperial romana; sin datos.

TARACENA AGUIRRE 1929:44, Lám. X, fot. inf, abajo, y 43-44, Lám. X. SANZ MíNGUEZ (1998:338339). BLANCO GARCÍA 2001 (e.p):113, fig. 5,9.

\section{Cat. 47}

LANGA DE DUERO (296). Soria, reg. 12. TERRACOTA (BULTO R.). Figura exenta.

Segortia Lanca-Las Quintanas. Peculiar figura de équido. Patas dispuestas en hilera. Modelada en arcilla roja bien cocida y pulimentada. Exvotos según Taracena Aguirre. Recientemente restaurada para ser expuesta en la muestra veneciana sobre Los Celtas. Recuerda a las figuras vacceas. Retocada con navaja.

$6,4 \times 18,7 . \mathrm{E}$.

I a.C.-I d.C.; I a.C.-I d.C.

TARACENA AGUIRRE 1929:44, Lám. X, fot. inf. ALMAGRO GORBEA 1991:772, 460. BLANCO GARCíA 2001(e.p):113, fig. 5,10.

\section{Cat. 48}

MANOUS (EL CATLLAR) (1097) Tarragona, reg. 8. TERRACOTA (BULTO R.). ¿Figura exenta? En superficie. Camino de la Huerta. Fragmento de équido. Parte del torso. arranque de patas delanteras y muslos de un jinete. Modelada a mano. Paralelo presentado con otra figura que corresponde a una silueta de la parte posterior de un équido y el arranque de las patas, procedente de la excavación del fossat del Castell del Catllar, cronología finales s. XV.

$4 \times 3$,9. M.

Sin datos. s. II-I a.C. ?

OLLE, OTIÑA, VALVERDU 1997-98:27-40, fig.7. VERGES Y ZARAGOZA 1999.

\section{Cat. 49}

MAS PULLINA (PONTONS) (1098) Barcelona, reg. 8. TERRACOTA (BULTO R.). Figura exenta.

En el bosque, cerca de la fuente del Mas Pullina (Pontons), a $3 \mathrm{Km}$. de El Castellar. Fuente situada 
cerca del poblado de El Castellar. Figurita de équido a la que le faltan las dos patas izquierdas y punta de las orejas y cola. Barro cocido. Ferrer y Giró mantienen que es una cabra, opinión aceptada por Genera Monells y Balil.

Sin datos. B.

FERRER Y GIRO 1943:185-210, lám.I, fig.3. BALIL 1955-56:260. GENERA MONELLS 1988:225.

\section{Cat. 50}

MIRAFLORES (1106) Murcia, reg. 2. TERRACOTA (BULTO R.). Figura exenta.

Zona de colina 'de Miraflores', prolongada en el llano. Superficie. Fragmento de caballo, mitad anterior del tronco con arranque de patas delanteras y cuello. Montura redondeada que sobresale en relieve de la grupa del caballo. Arcilla cocida, pasta decantada de color marrón al exterior y beige al interior. Presenta un orificio circular que atraviesa longitudinalmente el cuerpo y solo se aprecia en la factura. Asociada a terracotas femeninas.

$3,78 \times 2,73 . \mathrm{M}$.

ss. I-II d.C.; ss. I-II d.C.

HERNÁNDEZ CARRIÓN, GIL GONZÁLEZ 1999:367-374. Lám. 1, MI-T-0001.

\section{Cat. 51}

MOLINO DE LA MÁQUINA (1107) Murcia, reg. 2. TERRACOTA (BULTO R.). Figura exenta sobre peana.

Con motivo de un nuevo tendido telefónico en carretera C-3213, por D. Pascual Lucas Montellón. Caballo sobre peana sin cabeza ni cola. Montura rectangular señalada con incisión antes de la cocción. Incisiones de crin en cuello. Barro cocido, realizado en molde bivalvo. Pasta depurada color beige claro al interior y al exterior. Asociadas a terracotas de figuraciones femeninas. Pieza concebida para ser vista lateralmente. Asociado a TSG.

$5,14 \times 5,35$. R. ¿I-IId.C.?; I-II d.C.

HERNÁNDEZ CARRIÓN, GIL GONZÁLEZ 1999:367-374. Lám. 2, MM-T-0001.

\section{Cat. 52}

MOLINO DE LA MÁQUINA (1107) Murcia, reg. 2. TERRACOTA (BULTO R.).Figura exenta.

Con motivo de un nuevo tendido telefónico en carretera C-3213, por Pascual Lucas Montellón. Caballo sin cabeza, patas y pecho. Conserva parte de la cola. Sin montura, sin decoración. Barro cocido. Pasta depurada de color beige y núcleo grisáceo en interior. Asociadas a terracotas de figuras femeninas. Asociado a TS Sudgálica.

$3,64 \times 6 . \mathrm{M}$.

is. I-II d.C?; I-II d.C.

HERNÁNDEZ CARRIÓN, GIL GONZÁLEZ 1999:367-374. Lám. 2, MM-T-0002.

\section{Cat. 53}

NAVARRÉS (1108). Valencia, reg. 1. TERRACOTA (BULTO R.). Figura exenta.

Encontrado al desmontar un terreno para rectificar el trazado de un brazal de riego y revestirlo de cemento, en un campo propiedad de Don José Boyer Rigla, situado en la partida de La Traviesa, a $50 \mathrm{~cm}$. de cota. Caballo al que le faltan la cabeza y parte de las patas. Destaca la "silla" y modelado de los cuartos traseros, cilíndrico. Decorado con trazos rectilíneos marrón oscuro, las crines y laterales. Barro bien cocido, pasta rojiza, algo porosa a la que se dio engobe amarillo claro que recubre la figura. Luego pintada en rojo/marrón oscuro. En 1955 Don Agustín Arguisuelas Marzo regaló al Museo S.I.P la figura de caballo. Debió llevar figura montada en él y cola pegada.

$7,8 \times 9,6 . R$.

Sin datos. Sin datos.

PLA BALLESTER 1956:285-291, fig. 1 y Lám. 1. 


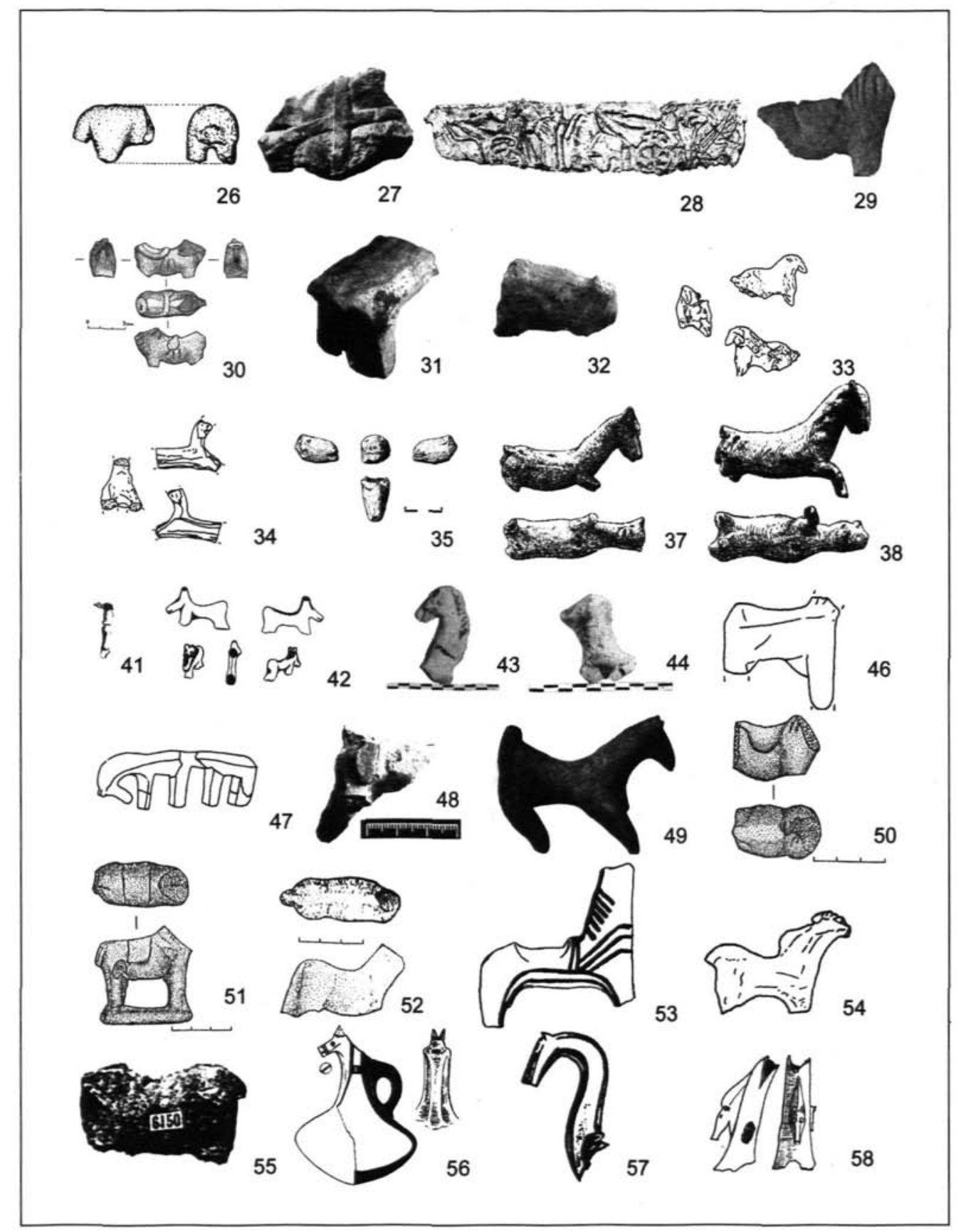

Lamina II. Terracotas de équidos en la Edad del Hierro. 


\section{Cat. 54}

NUMANCIA (Poblado) (299). Soria, reg. 12. TERRACOTA (BULTO R.). Figura exenta.

Sin datos sobre hallazgo. Figura de caballo con patas y cola fracturadas. Gran naturalismo, crines modeladas. Sin pintar. Modelada en barro. Según BLANCO GARCÍA, por los cuartos traseros parece un toro. Dibujo copia de foto de Schulten.

R.

s. II a.C.-s. I d.C.; ss. II a.C.-I d.C.

SCHULTEN 1914-31: taf.36, B, 6152. WATTENBERG SANPERE 1978: fig.14,3, centro. BLANCO GARCÍA 2001:113. fig.5.7.

\section{Cat. 55}

NUMANCIA (Poblado) (299). Soria, reg. 12. TERRACOTA (BULTO R.). Figura exenta.

Sin datos sobre hallazgo. Muy desgastado, pero mantiene modelado en cola y arranque de las patas. Arcilla cocida.

M.

ss. II a.C.-I d.C.; ss. II a.C.-I d.C.

SCHULTEN 1914-31: taf.36, B, 6150.

\section{Cat. 56}

NUMANCIA (Poblado) (299). Soria, reg. 12. TERRACOTA (BULTO R.). Fragmento de asa de jarra.

Sin datos sobre hallazgo. Cabeza de équido, que sirve de pico vertedor en jarra numantina, completa. Restos de pintura que marcan la cabezada, los ojos y orejas. Modelado en arcilla, pintada y cocida.

19. E.

ss. II a.C.-I d.C.

WATTENBERG SANPERE 1963: 211, 1149, tab. XLIV, 1149, Lám. fot XII. BLANCO GARCÍA 2001(e.p): 110 , fig. 4,2 .

\section{Cat. 57}

NUMANCIA (Poblado) (299). Soria, reg. 12. TERRACOTA (BUlTO R.). Asa de simpulum.

Sin datos sobre hallazgo. Fragmento de asa de simpulum en forma de prótomo de caballo. Extremo de mango en forma de caballo, sin el cuenco al que sirve. Marcados los ojos, orejas y brida. ¿pintada?. Arcilla parduzca modelada. Tipo III de Martín Valls.

7,5. M.

ss. II a.C.-I d.C.; ss. II a.C.-I d.C.

SCHULTEN 1931: taf.36, B 6144. WATTENBERG SANPERE 1963:171, n. 465, tab.XVII,465, Lám. XII,3. MARTIN VALLS 1990: 148,31. LORRIO 1997:243 y Fig. 103. BLANCO GARCIA 2001 (e.p): 110, fig. 4,3.

\section{Cat. 58}

NUMANCIA (Poblado) (299). Soria, reg. 12. TERRACOTA (BULTO R.). Aplique sobre 'trompa de guerra'.

Sin datos sobre hallazgo. Objeto normalmente llamado "trompa de guerra". Aplique decorativo en arcilla. Hocico ancho y abultado, orejas no tan puntiagudas, ojos saltones. La quijada bien señalada y cuello de caballo. Arcilla modelada, rojo parduzca. A torno. Interpretada por Wattenberg Sanpere como figura de lobo. Según Blanco como caballo.

$11,5 \times 5,5$. B.

ss. II a.C.-I d.C.

WATTENBERG SANPERE 1963:169, 430, tab.XVI,430, Lám.fot. X,1. BLANCO GARCÍA 1997:190. BLANCO GARCÍA 2001(e.p):111, fig.4,9. 


\section{Cat. 59}

NUMANCIA (Poblado) (299). Soria, reg. 12. TERRACOTA (BULTO R.). ¿Pesa? ¿fusayola?

Sin datos sobre hallazgo. ¿fusayola? o ¿pesa de telar? en forma de cabeza de caballo. Perforada en su base redondeada. Cabezada y crines pintados con trazos muy geométricos. Arcilla modelada rojoamarillenta, y pintada. Se discute la función de la pieza, debido a su orificio.

$4 \times 5,5$. B.

ss. II a.C.-I d.C.; s. I a.C.

WATTENBERG SANPERE 1963:171,464, tab. XVII, 464. ALONSO Y BENITO 1991-92:533. LORRIO 1997:243 y Fig. 103.8. BLANCO GARCÍA 2001 (e.p):112, fig.4,11.

\section{Cat. 60}

NUMANCIA (Poblado) (299). Soria, reg. 12. TERRACOTA (BULTO R.). Cabeza de caballo sobre peana en forma de planta de pie.

Sin datos sobre hallazgo. Exvoto en forma de cabeza de caballo sobre base en forma de planta pedis, decorada, el hocico vuelve a la pieza. Barro pardo, quemado.

4,6. E.

ss. II a.C.-I d.C.; I a.C.

WATTENBERG SANPERE 1963:170,458, tab. XVII, 458, Lám. fot. XII, 4. SCHULTEN 1931: taf. 36,B. ALONSO Y BENITO 1991-92:533. LORRIO 1997:243 y Fig. 103.11. BLANCO GARCÍA 2001 (e.p):112, fig. 4,12 .

\section{Cat. 61}

NUMANCIA (Poblado) (299). Soria, reg. 12. TERRACOTA (BULTO R.). Cabeza de caballo sobre peana en forma de planta de pie.

Sin datos sobre hallazgo.

Esbelta y muy estilizada, con base en forma de planta pedis. Modelada en arcilla.

11,5. E.

ss. II a.C.-I d.C.; ss. II a.C.-I d.C.

TARACENA 1925: 87, Lám. 13. WATTENBERG SANPERE 1963:170, n. 457, tab. XVII, Lám. fot. XII, 5. ORTEGO FRIAS 1985:142, fot. inf. izq. SCHULTEN 1931: taf.36, A1. 6165. ALONSO Y BENITO 199192:533. LORRIO 1997:243 y Fig. 103.10. BLANCO GARCÍA 2001(e.p):112. fig. 4,13.

\section{Cat. 62}

NUMANCIA (Poblado) (299). Soria, reg. 12. TERRACOTA (BULTO R.). Figura exenta.

Sin datos sobre el hallazgo. Figura equina con cabeza agachada, cola fragmentada y parte de las extremidades. Modelada a mano cuidadosamente en arcilla roja-negruzca. Desconocimiento de funcionalidad.

$3,5 \times 4,5 . \mathrm{E}$.

ss. II a.C.-I d.C.; s. I a.C.

TARACENA 1925:87, Lám. 13. SCHULTEN 1931: taf. 36, B 6151. WATTENBERG SANPERE 1963:171, 461, tab. XVII, 461. ALONSO Y BENITO 1991-92:533. LORRIO 1997:243 y Fig. 103.12. BLANCO GARCÍA 2001 (e.p):112, fig. 5,1.

\section{Cat. 63}

NUMANCIA (Poblado) (299). Soria, reg. 12. TERRACOTA (BULTO R.). Figura exenta.

Sin datos sobre el hallazgo. Figura equina a la que le faltan el extremo de las patas y la cola. Cuello alargado con hocico puntiagudo. Orejas y cola fragmentadas en parte. Arcilla modelada de color rojizo-negruzco. Funcionalidad desconocida, forma objeto aislado.

5,5. R.

ss. II a.C.-I d.C.; s. I a.C.? 
TARACENA 1925: 87, Lám. 13. SCHULTEN 1931: taf. 36, B 6158. WATTENBERG SANPERE 1963:171, 463, tab. XVII, 463, Lám. fot. XIII, 5. MARCO SIMÓN 1989:117. ALONSO Y BENITO 199192:533.LORRIO 1997:243 y Fig. 103.13 BLANCO GARCÍA 2001 (e.p): 112, fig.5,2.

\section{Cat. 64}

NUMANCIA (Poblado) (299). Soria, reg. 12. TERRACOTA (BULTO R.). Figura exenta.

Sin datos sobre el hallazgo. Caballo de medidas desproporcionadas, cuerpo muy grande y cabeza pequeña. Hocico puntiagudo. Arcilla.

M.

ss. II a.C.-I d.C.; s. I a.C ?

SCHULTEN 1914-31:269, taf.36. ALONSO Y BENITO 1991-92:533.

\section{Cat. 65}

NUMANCIA (Poblado) (299). Soria, reg. 12. TERRACOTA (BULTO R.). Figura exenta.

Sin datos sobre el hallazgo. Cabeza de caballo con orejas puntiagudas, le falta todo el cuerpo, sólo se conserva parte del cuello y la cabeza muy bien modelada resaltando hocico y orejas. Modelado en arcilla.

R.

ss. II a.C.-I d.C.; s. I a.C.?

WATTENBERG SAMPERE 1963:lám- fot. XII,3. COMISIÓN EJECUTIVA 1912:36, Lám. LIV. ALONSO Y BENITO 1991-92:533.

\section{Cat. 66}

NUMANCIA (Poblado) (299). Soria, reg. 12. TERRACOTA (BULTO R.). Figura exenta ¿de caballo?.

Sin datos sobre el hallazgo. Cuerpo ¿de caballo? al que le faltan la cabeza, la cola y parte de las patas. Se marca parte las crines y la cola. Arcilla modelada.

M.

ss. II a.C.-I d.C.; s. I a.C.?

COMISIÓN EJECUTTVA 1912:36, Lám. LIV. ALONSO Y BENITO 1991-92:533.

\section{Cat. 67}

NUMANCIA (Poblado) (299). Soria, reg. 12. TERRACOTA (BULTO R.). Figura exenta de cuadrúpedo. Sin datos sobre el hallazgo. Cuadrúpedo; animal muy desgastado al que le faltan parte de las patas y la cola. Arcilla modelada muy desgastada.

M.

ss. II a.C.-I d.C.; s. I a.C.?

COMISIÓN EJECUTIVA 1912:36, Lám. LIV. ALONSO Y BENITO 1991-92:533.

\section{Cat. 68}

PALENZUELA (258) Palencia, reg. 12b. TERRACOTA (BUlTO R.). Asa de simpulum.

Sep. 3, parte del ajuar. Sector N-50. Simpulum completo. Extremo de mango en forma de caballo, con cuenco al que sirve. Con indicación de ojos y orejas. No hay cabezada pintada. Cabeza muy cuidada. Crines simuladas con impresiones de punzón. Modelada en arcilla anaranjada. Vaso a torno. Vaso de ajuar funerario con simbolismo religioso relacionado con ritos de paso hacia la otra vida. Tipo IIIb de Martín Valls. Inspirado en ejemplares helenísticos según Martín Valls. E.

II-I a.C.; II-I a.C.

MARTÍN VALLS 1990:147,15, fig. 1, III .BLANCO GARCÍA 2001(e.p):110, fig. 4,4. 


\section{Cat. 69}

PALENZUELA (258) Palencia, reg. 12b. TERRACOTA (BULTO R.). Asa de simpulum.

Tumba 25, Sector N-50. Simpulum completo. Extremo de mango en forma de caballo con cuenco al que sirve. Detalle de ojos y orejas puntiagudas. Modelado en arcilla. Vaso de ajuar funerario con simbolismo religioso relacionado con ritos de paso hacia la otra vida. Tipo III-b Martín Valls.

$\mathrm{E}$

II-I a.C.

MARTIN VALLS 1990: 147,16, fig.3,4. BLANCO GARCÍA 2001(e.p):110, fig.4,5.

\section{Cat. 70}

PALENZUELA (258) Palencia, reg. 12b. TERRACOTA (BULTO R.). Asa de simpulum.

Procede de ajuar funerario. Hallado antes del inicio de las excavaciones oficiales. Fragmento de simpulum. Extremo fragmentado de mango en forma de cabeza de caballo, sin el cuenco al que sirve. No se aprecian detalles ni pintura ni modelado. Modelado en arcilla. Barro cocido anaranjado. Posible funcionalidad en ajuar funerario, con simbolismo religioso relacionado con ritos de paso hacia la otra vida. Tipo III-b Martín Valls.

Longitud de la cabeza, $2,9 \mathrm{~cm}$. R.

II-I a.C.

CASTRO GARCÍA 1971:23, Lám. XV, 48. CASTRO GARCÍA 1972:139, fot.46. MARTÍN VALLS 1990:146, n. 9. SÁNCHEZ MORENO 1995-96:215. ALONSO Y BENITO 1991-92:533. BLANCO GARCÍA 2001 (e.p):110, fig. 4,6.

\section{Cat. 71}

PALENZUELA (258) Palencia, reg. 12b. TERRACOTA (BULTO R.). Asa de simpulum.

En ajuar funerario, previo a las excavaciones. Simpulum. Fragmento del asa con figuración equina. Fragmento de extremo de mango en forma de cabeza de caballo sin el cuenco al que sirve. Sin decoración ni modelado de detalles. Modelado en arcilla. Para ajuar funerario con simbolismo religioso relacionado con ritos de paso hacia la otra vida.

R.

II-I a.C.

CASTRO GARCÍA 1972:139, fot.45. BLANCO GARCÍA 2001(e.p):110, fig. 4,7.

\section{Cat. 72}

PALENZUELA (258) Palencia, reg. 12b. TERRACOTA (BULTO R.). Asa de simpulum.

En ajuar funerario. Simpulum. El mango imita el cuello de un caballo con incisiones simulando crin. No se conserva el extremo distal, la parte de la cabeza propiamente dicha, pero sí las crines del cuello y el cuenco al que servía el mango. Recipiente coniforme. Modelada en arcilla, barro rojo anaranjado hecho a mano. Vaso de ajuar funerario con simbolismo religioso relacionado con ritos de paso hacia la otra vida.

Diámetro de la boca: $3,5 \mathrm{~cm} .3,5 \times 7 . \mathrm{M}$.

II-I a.C.

CASTRO GARCÍA 1971:23. Lám XV, 47. CASTRO GARCÍA 1972:139, fot.41. ¿MARTÍN VALLS 1990:147,17?. SÁNCHEZ MORENO 1995-96:215. ALONSO Y BENITO 1991-92:533. BLANCO GARCIA 2001(e.p):110-111, fig.4,8.

\section{Cat. 73}

LA PEDRERA (POBLADO) (2072). Lérida, reg. 10. TERRACOTA (BULTO R.). ¿Morillo?

Estrato III del Corte estratigráfico de 1958. 'Fragmento parte posterior cilindro macizo, representando cuartos traseros cuadrúpedo con cola (¿équido?). Morillo. Perforación en la base de las patas. Para Maluquer et al., resto de morillo. Arcilla compacta cocida y restos de pintura roja.

$10,5 \times 6,1 . M$. 
s. VIII-ppios. II a.C.; s. IV a.C. Por asociación estratigráfica a cerámica ática.

MALUQUER, MUÑOZ, BLASCO 1960:44 y fig. 15. MALUQUER 1963: Lám. IIIA. PALLARÉS 1965:98. GALÁN DOMINGO 1989-90:184.

\section{Cat. 74}

PENYA DEL MORO (S. JUST DESVERN) (2008). Tarragona, reg. 8. TERRACOTA (BULTO R.). Figura exenta.

Sector A (550-500 a.C). A 22.3.81. Cabeza de équido, orejas aplicadas con pastillas de barro. Incisiones en el cuello ¿bridas?. Tierra cocida, arcilla basta.

$3,9 \times 4,5 . \mathrm{M}$.

c. 600-c. 300 a.C.; c. 550-500 a.C. En Barbera, Sanmartí 1982, contexto del s. VI a.C.

BARBERA, SANMARTí 1982:29, 67 y 71, Lám. XXIX, fig.12. VILÁ 1994: 144 y Fig. 5. OLLE, OTIÑA, VALLVERDU 1997-98:27-40, fig. 4. BARBERA FARRÁS 2000:69.

\section{Cat. 75}

PENYA DEL MORO (SANT JUST DESVERN) (2008). Tarragona, reg. 8. TERRACOTA (BULTO R.). Figura exenta cuadrúpedo ¿équido?.

Sector A (550-500 A.C). A 79180. Fragmento de équido? (¿bóvido?). Arcilla roja, desgrasantes orgánicos. $3,02 \times 1,48 . \mathrm{M}$.

c. 600 -c. 300 a.C.; c. $550-500$ a.C. Barbera, Sanmartí 1982 , contexto del s. VI a.C.

BARBERA Y SANMARTI 1982:114, Lám. XXIX, fig.11. VILÁ 1994:141-149.

\section{Cat. 76}

PENYA DEL MORO (SANT JUST DESVERN) (2008). Tarragona, reg. 8. TERRACOTA (BULTO R.). Figura exenta.

Sector D Alt (425-300 aC) DA 149. Parte media anterior de un caballo. Le faltan patas y cabeza, se muestra musculatura y crines. Arcilla exteriormente negro y roja al interior. Modelado vigoroso.

$4,9 \times 2,84 . \mathrm{M}$.

c. 600 -c. 300 a.C.; $425-300$ a.C

BARBERÁ Y SANMARTÍ 1982:114, Lám. LXIV, fig.2. VILÁ 1994:141-149.

\section{Cat. 77}

PENYA DEL MORO (SANT JUST DESVERN) (2008). Tarragona, reg. 8. TERRACOTA (BULTO R.). Figura exenta cuadrúpedo. ¿équido?.

Sector D Alt (425-300 a.C). DA 148. Cuartos traseros de animal (¿bóvido?, ¿aplique...?.) Tierra cocida, arcilla y desengrasantes de pizarra abundantes.

$3,9 \times 2,3 . \mathrm{M}$.

c. 600 -c. 300 a.C.; $425-300$ a.C.

VILÁ 1994:141-149. BARBERA Y SANMARTI 1982, Lám. LXIV, fig.1.

\section{Cat. 78}

PUIG CASTELLAR (158). Barcelona, reg. 8. TERRACOTA (BULTO R.). Figura exenta.

En superficie, en el camino de la Huerta. Equido al que le faltan las extremidades y cabeza. Sin atalajes, ni silla. Cola ancha y corta. Orificio en el vientre (posible colocación sobre plinto o peana). Arcilla cocida. Se piensa que carecía de atalajes (BALIL) porque no hay silla. No es juguete, posible objeto de culto (yacimiento posible santuario). (Balil). Genera indica que pertenece la colección Sagarra.

$9 \times 5,1 . M$.

Fin V-fin I a.C.; s. II-I a.C. Contexto romano-republicano.

BALIL 1956:255-256. Lám. I, fig.3. GENERA 1988:225. VILÁ 1994:147. OTIÑA 1999. OLLE, OTIÑA,VALLVERDU 1997-98:27-40. 


\section{Cat. 79}

RAUDA (ROA DE DUERO) (1028). Burgos, reg. 12b. TERRACOTA (BULTO R.). ¿Simpulum?.

Escombrera de la Cruz de San Pelayo. Prótomo de caballo de forma arqueada. Partido por ambos extremos y le falta la cabeza. Arcilla cocida y bien depurada beige-parda, y ipintada? en líneas negras. Parece constituir el extremo decorado de un objeto de características distintas, con funcionalidad propia. Podría pertenecer a extremo de simpulum de arcilla.

$5,5 \times 3,5 . \mathrm{M}$.

s. II-meds. I a.C.

SACRISTÁN DE LAMA 1986:206, Lám. LXX, 8. SÁNCHEZ MORENO 1995-96:215. ALONSO Y BENITO 1991-92:533. SANZ MÍNGUEZ 1998:338. BLANCO GARCÍA 2001 (e.p):113, fig.5,13.

\section{Cat. 80}

ROQUES DE SANT FORMATGE (1109). Lérida, reg. 10. TERRACOTA (BULTO R.). Figura exenta. En corte estratigráfico, Nivel IVA. Figurita de équido sin cabeza, patas ni cola. Proporciones macizas, podría ser un bóvido. Pasta anaranjada sin restos de decoración. Cocción desigual. Posible bóvido. $4,5 \times 6,3 . \mathrm{M}$.

Ppios. s. IV-fin III a.C.; mediados s. IV. a.C. Datación por estratigrafía controlada. Asociado a Barniz Negro ático.

VILÁ 1994:141-149. JUNYENT 1973:381 y Fig. 28.

\section{Cat. 81}

RUBI (1110) Barcelona, reg. 8. TERRACOTA (BULTO R.). Morillo.

Excavaciones de J. Colominas en Rubí, casi inéditas. Turó num. 2, Silo 10 (según J. Colominas). Parte trasera de un morillo perforado. Se indica la cola de un cuadrúpedo (¿caballo?). Arcilla.

M.

Sin datos; sin datos.

MALUQUER 1963:37, Fig. 5. GALÁN DOMINGO 1989-90:184.

\section{Cat. 82}

LAS RUEDAS (PADILLA DEL DUERO) (262). Valladolid, reg. 12b. TERRACOTA (BULTO R.). ¿simpulum?

IIAH/60. Material en posición secundaria. Cabeza de caballo, falta todo el cuerpo, se marcan las orejas. ¿Simpulum o prótomo?. Orejas rotas. Morro indicado por profunda incisión. Crines con resalte central. Arcilla modelada. Pasta parduzca bien decantada y compacta. Puede que alguna de las figuras de esta necrópolis corresponda a équidos pero sin seguridad. Parece ser el extremo decorado de un objeto con características distintas, con funcionalidad propia. ¿Simpulum?

18. R.

Ppios s. IV- fin. I a.C.; sin datos.

SANZ MÍNGUEZ 1998:175, 337-339, fig. 171, inv. 547. BLANCO GARCÍA 2001 (e.p):114, fig.5,14.

\section{Cat. 83}

LAS RUEDAS (PADILLA DEL DUERO) (262). Valladolid, reg. 12b. TERRACOTA (BULTO R.). Figura exenta.

IIAG/46. Material en posición secundaria. Fragmento cortado con navaja a bisel, como en Langa. ¿parte de caballo?. Decoración excisa de zig-zag (¿crines?). Arcilla modelada. Pasta gris bien decantada y compacta.

2. D.

s. IV-I a.C.; sin datos.

SANZ MÍNGUEZ 1998:175, 337-339, fig. 171, inv. 544. 


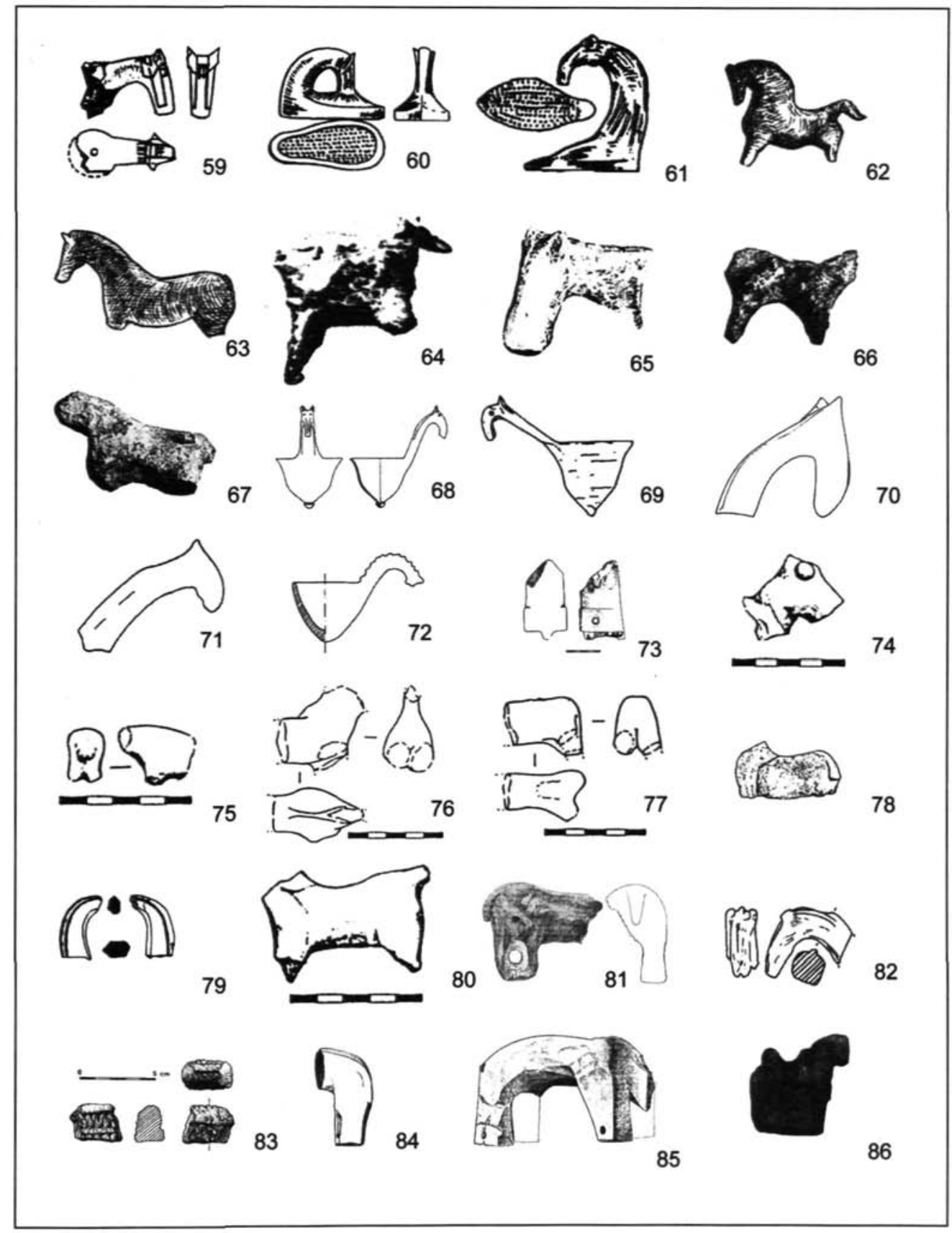

Lámina III. Terracotas de équidos en la Edad del Hierro. 


\section{Cat. 84}

SAN ANTONIO DE CALACEITE (217). Teruel, reg. 7. TERRACOTA (BULTO R.). ¿Morillo? ¿Figura exenta?

Excavaciones de Bosch Gimpera en 1915-1919, pero de labores de limpieza entre dos rocas cerca de la calle Sur. Cuartos traseros de équido (?) con trazas de la cola. Perforación en las patas, según Pallarés 'para colgar como si fuera un amuleto'. Según Maluquer sería parte de un morillo. Barro cocido. Restos de pintura roja. Otro dibujo de mejor calidad en Maluquer (1963:Fig.6).

$\mathrm{M}$

s. VII-II a.C.; ¿s. IV a.C.? Fecha por paralelo con La Pedrera. Debatible.

MALUQUER DE MOTES 1963:37, Fig. 6 y Lám Vb. PALLARÉS SALVADOR 1965:97-98, 130 y fig.130.

GALÁN DOMINGO 1989-90:184.

\section{Cat. 85}

SAN ANTONIO DE CALACEITE (217). Teruel, reg. 7. TERRACOTA (BULTO R.). Morillo ¿équido?.

Excavaciones del IEC. Morillo zoomorfo (;équido?) muy esquemático. Barro muy depurado y compacto.

M

s. VII-II a.C.; sin datos (según Galán, s. II a.C.).

MALUQUER DE MOTES 1963:37, Fig. 4, Lám. II. GALÁN DOMINGO 1989-90:184.

\section{Cat. 86}

SAN MIGUEL DE LIRIA (109). Valencia, reg. 6. TERRACOTA (BULTO R.). Figura exenta. ¿Romana? Ladera sur del cerro, sin contexto arqueológico definido, en superficie. Escultura en forma de caballo enjaezado, en posición estática. Es posterior a época ibérica, aunque se ha publicado como del s. IV-III a.C. Cabeza mal conservada, le falta el hocico. Crin con incisiones verticales, cola larga. Lleva montura y brida. No bocado. Se empleó "tabique de refuerzo" entre patas y bajo vientre. Realizado a base de molde bivalvo. Posible falso o romano. Puede ser exvoto u ofrenda procedente de un posible santuario ibérico no descubierto en el cerro de San Miguel de Liria. Se parece a los del grupo 3 y 5 de Cuadrado.

S. IV según Aldana.

6 x 4.5. E. ss. IV-III a.C. Moderno o romano.

ALDANA NACHER 1984:82.

\section{Cat. $86 b$}

SAN MIGUEL DE LIRIA (109) Valencia, reg. 6. TERRACOTA (BULTO R.). Figura exenta.

Caballito. Patas y cola rotas. Con arreos. Crin realizada pellizcando la arcilla. Frontalera y faleras realizadas con dos discos de arcilla aplicados. Para $\mathrm{H}$. Bonet los discos laterales serían los ojos. Pasta marrón grisácea.

$5,8 \times 7,8$. B.

Probablemente fines del s. III a.C. o principios del II.

BONET (1995:484, 295 y Fig. 145).

\section{Cat. $86 \mathrm{c}$}

SAN MIGUEL DE LIRIA (109) Valencia, reg. 6. TERRACOTA (BULTO R.). Figura exenta.

Caballo con jinete perdido. Le faltan además cabeza, cola y patas. Restos que indican las piernas de un jinete modelado aparte.

Pasta marrón-gris-marrón. Muy rodado.

$7,5 \times 11 . M$.

Probablemente fines del s. III a.C. o principios del II.

BONET (1995:484, Fig. 105). 


\section{Cat. 87}

SAITABI (1101). Valencia, reg. 1. TERRACOTA (BULTO R.). Figura exenta.

Hallado de forma casual al realizar una zanja. Caballo al que le faltan la cabeza, las articulaciones inferiores de las patas traseras y casi la totalidad de las delanteras. Decoración del cuello con líneas en zig-zag (crines y parte del cuerpo). Crines en rojo, enmarcadas por dos líneas paralelas en negro o marrón oscuro. Arcilla amarillo-verdosa clara, con engobe amarillo mas pintura roja en crines y marrón en laterales. Según Chocomeli, los detalles figurativos tienen analogía con los empleados en cerámica de Liria.

9. R.

Sin datos. Sin datos.

CHOCOMELI GALÁN 1940:6-9, fig.1. PLA BALLESTER 1956:285-291, fig. 2.

\section{Cat. 88}

SAITABI (1101). Valencia, reg. 1. TERRACOTA (BULTO R.). Figura exenta ¿romana?.

Encontrado por un obrero en una zanja, en las cercanías de Játiva. Parte de un caballo del que se conservan parte del cuello, cuerpo, cola y parte de las patas traseras. En relieve la montura, crines y cola. Silla de montar. Barro cocido, pasta fina, compacta y uniforme. Romana si no posterior. M.

Época romana o posterior.

CHOCOMELI GALÁN 1940:6-9, fig.2.

\section{Cat. 89}

SELVA DEL CAMP (1112). Tarragona, reg. 8. TERRACOTA (BULTO R.). Figura exenta.

En superficie, finca del Camino de la Huerta, sudeste del núcleo urbano de Selva del Camp. Caballo y parte del jinete (parte) con patas fracturadas. Con orificio cuadrado de $0.3 \mathrm{~cm}$. sin función evidente. Modelado a mano, pasta de color marrón claro con desgrasantes blancos y mica. Recubierto de engobe blanco. Inédito. Asociada a material cerámico. Posible silbato por paralelos con piezas similares del s.XIV.

$5,5 \times 4,5 . R$.

Sin datos; s. II-I a.C.

OLLE, OTIÑA, VALVERDU 1997-98:27-40, Fig.4.

\section{Cat. 90}

SIMANCAS (1071) Valladolid, reg. 12b. TERRACOTA (BULTO R.). Figura exenta.

Fuera de contexto. Cabeza de caballo, bocina o tobera?. Falta el cuerpo, se marcan mucho las orejas. Técnica biselada. Modelada sobre barro nuez claro. No sabemos a que tipo de objeto puede pertenecer. Wattenberg dice que es parte de una bocina celtibérica, o tobera. Sanz Mínguez disiente con razón y cree que perteneció a una pieza exenta.

8,5. M.

Sin datos; 75-29 a.C.

WATTENBERG SAN̄PERE 1978:60 y 63, 41 y Lám. IV. SÁNCHEZ MORENO 1995-96:215. ALONSO Y BENITO 1991-92:533. SANZ MÍNGUEZ 1998:338. BLANCO GARCÍA 2001(e.p):113, fig.5,13.

\section{Cat. 91}

TARRAGONA (C. APODACA) (1091). Tarragona, reg. 8. TERRACOTA (BULTO R.). Figura exenta. Excavación Calle Apodaca, 7. Cuadrúpedo fragmentado en tres partes. Probablemente équido. Le falta la cabeza, cola y parte de las extremidades. Fragmentada y pegada. Arcilla cocida. Posible santuario por un ara (?) de adobe. Puche dice que es cuadrúpedo pero sin identificar especie.

6. M.

Ss. II-I a.C.; $1 / 2$ s. II a.C. Contexto romano-republicano, asociada a cerámica calena y un cerno de Core. PUCHE 1997:243. OLLE, OTIÑA, VALVERDU 1997-98: 27-40. 


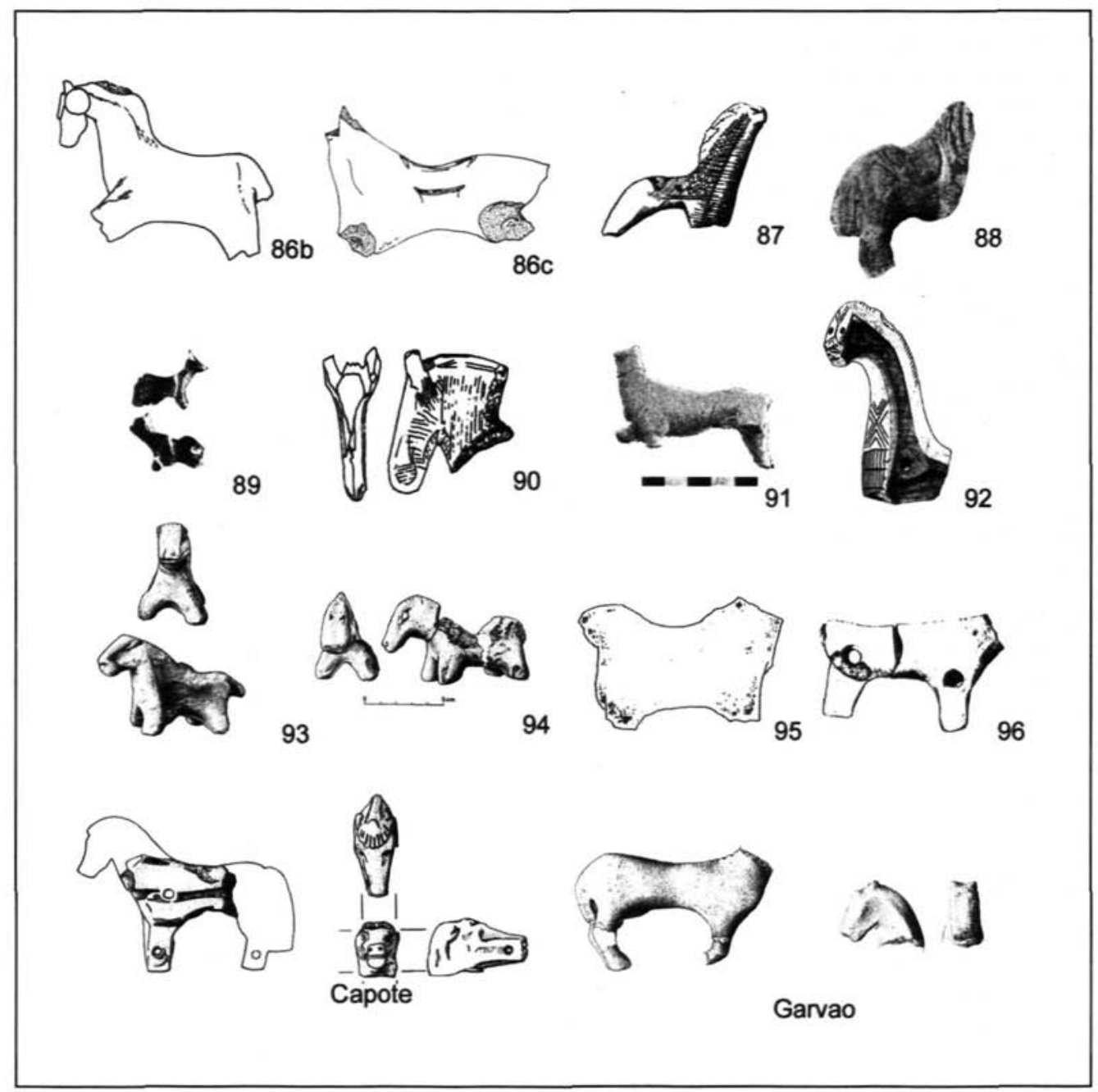

Lámina IV. Terracotas de équidos en la Edad del Hierro. 


\section{Cat. 92}

TOSSAL DEL MORO (PINYERES) (490). Tarragona, reg. 7. TERRACOTA (BULTO R.). Morillo.

En las excavaciones de Pérez Temprado (según J. Maluquer de Montes). Morillo en forma de équido. El morro está destruido y tiene un orificio en la base del cuello y los ojos marcados mediante agujeros. Decoración geométrica incisa. Cortado a bisel, como si fuera de madera (Maluquer). Barro muy decorado y compacto. Decoración incisa.

18. E.

VII-VI en adelante. s. VI a.C.? No hay precisión para la cronología.

ARTEAGA, PADRO, SANMARTÍ 1990:135,167, fig.67. MALUQUER DE MOTES:1963:13 y Fig. 3.

\section{Cat. 93}

TOSSAL DEL MORO (PINYERES) (490) Tarragona, reg. 7. TERRACOTA (BULTO R.). Figura exenta. Campaña de excavaciones de 1975 y 1977. TM 75/2. Figura de caballo al que faltan las crines, y orejas, las patas y cola cortas. Marcado el hocico y la manta, la cola y las patas. La boca se representa por un orificio. Muy desgastado. Arcilla modelada de color beige claro. Posibilidad de llevar jinete. $5,60 \times 9,40$. B.

ppios. s.V - ?. s.V a.C. Iberico Fase II, con urnas de orejetas y BN s. V (delicate class, copa-escifo). ARTEAGA, PADRÓ, SANMARTí 1990:106 y 113, fig. 38 y 61. VILÁ 1994:147.

\section{Cat. 94}

TOSSAL DEL MORO (PINYERES) (490). Tarragona, reg. 7. TERRACOTA (BULTO R.). Figura exenta. Campaña de excavaciones de 1975 y 1977 . TM 75-2. Figura de caballo fragmentada por el cuello y le falta la parte del lomo. La grupa es curva posiblemente llevaría jinete. Representación de ojos, morro y boca, orejas aplicadas en forma de pastillas. Muy desgastado y sin cola. Arcilla modelada. Posibilidad de llevar jinete.

$5,8 \times 10,6 . \mathrm{B}$.

ppios. s. V-?; s. V a.C. Ibérico Fase II, con urnas de orejetas y BN s. V (delicate class, copa-escifo). ARTEAGA, PADRÓ, SANMARTí 1990:113, fig.38 y 61. VILÁ 1994:14. 7. GENERA 1988:225.

\section{Cat. 95}

LOS VILLARES DE CAUDETE (112). Valencia, reg. 6. TERRACOTA (BULTO R.). Figura exenta. Hallazgo en Superficie. Probable équido, aunque muy grueso. Faltan patas y cabeza. Sin arreos ni jinete.

M

Fin del s. V-s II a.C. Sin datos más precisos.

MATA PARREÑO (1991:178 y Fig. 93).

\section{ADDENDUM}

\section{Cat. 96}

CERRO MACARENO (185). Sevilla, reg. 17. TERRACOTA (BULTO R.). Figura exenta.

Cuadrúpedo. Falta cabeza y patas traseras. Dos perforaciones horizontales en el punto en que las patas se unen al torso. Probablemente équido. Restos de pintura marrón.

$6 \times 8,5 . M$.

Nivel 18 de Cerro Macareno, fechado por cerámica a fines del s. VI a.C. Quizá más reciente. PELLICER, ESCACENA, BENDALA (1983:41 y Fig. 56). 


\section{DISTRIBUCIÓN DE LOS HALLAZGOS}

En la Figura 2 se recoge la dispersión de los yacimientos con hallazgos del tipo que nos ocupa, sin indicar número de ejemplares ni tipos. Se han excluido dos piezas que consideramos no corresponden a équidos aunque a veces se hayan considerado tales (nos. cat. 23 у 39 ).

El primer rasgo que llama la atención es la concentración de hallazgos en el área catalana, zona turolense y del Bajo Ebro, Levante meridional y Sureste, y cuencas alta y media del Duero. En cambio, son muy escasos o inexistentes los ejemplos en el curso medio y alto del Ebro, zona pirenaica, área de Valencia-Castellón y toda Andalucía y Meseta Sur.

No nos cabe duda de que en buena medida la distribución conocida refleja la existencia, desde principios del siglo $\mathrm{XX}$, de grupos de investigación muy activos y que han venido realizando numerosas excavaciones en contextos de poblado, en Cataluña, cuenca baja del Ebro, zona celtibérica y Sureste. Sin embargo, también han sido intensas las investigaciones en Andalucía y Valencia-Castellón, sin que el mapa de hallazgos refleje una densidad comparable de figuras de équidos en arcilla. Por otro lado, hay numerosos yacimientos importantes, y en los que se han practicado excavaciones arqueológicas de importancia en los últimos años, que todavía no han sido objeto de publicación detallada, por lo que cabe la posibilidad de que parte de estos huecos se rellenen pronto[s].

En conjunto pues creemos que la Figura 2 refleja parcialmente la intensidad diferencial de la investigación por regiones (y en particular la excavación de contextos de hábitat por oposición a necrópolis), pero creemos también que estos desequilibrios en la investigación no acaban de explicar la ausencia de este tipo de objetos en regiones como Andalucía, Levante septentrional y cuenca media y alta del Ebro, donde las investigaciones también han sido intensas.

En particular, cabe pensar que en el área andaluza, donde se conocen numerosísimas imágenes de équidos en forma de relieves pétreos (en especial en el área cordobesa y granadina) y de exvotos en bronce (santuario de Despeñaperros), las figuras en barro no fueran populares por la modestia de su material. Sin embargo veremos enseguida que el contexto de aparición de los équidos de arcilla -fundamentalmente poblados- es diferente del de los exvotos de bronce o piedra-santuarios sobre todo-, y que por tanto esta solución es simplista y probablemente no explica la distribución conocida.

[5] Insistimos en que hay amplias regiones donde también se conocen équidos de arcilla que aquí no hemos recogido. Es el caso de Extremadura o sur de Portugal, donde el Castrejón de Capote ha proporcionado algunos ejemplares (según Berrocal, 1992:122 y Fig. 19; 1995). Lo mismo ocurre en el depósito de Garvao, donde aparecieron otras dos representaciones de caballitos (Beirao et al. 1985). 


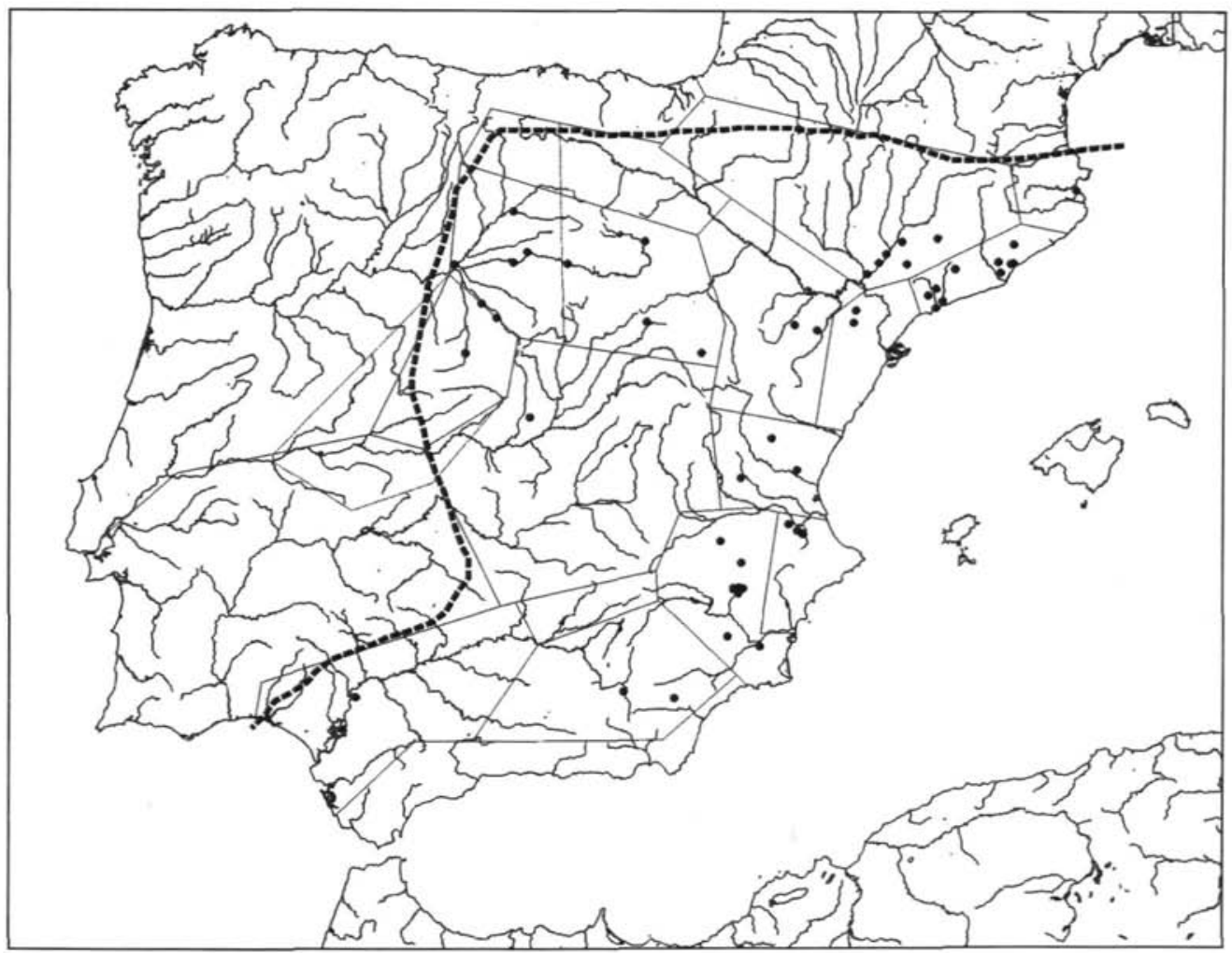

Figura 2: Distribución de yacimientos con terracotas de équidos.

\section{ÍNDICE POR REGIONES Y ÁREAS GEOGRÁFICAS:}

Tras el nombre de yacimiento se indica, entre paréntesis, el número de catálogo. Si la pieza es muy dudosa (porque el carácter de équido o la cronología prerromana son muy discutibles), se indica subrayado.

\section{ANDALUCÍA:}

Región 3: Baza (6), Gaspares (42).

Región 4: -

Región 5: -

Región 17: Cerro Macareno (96).

\section{SURESTE:}

Región 2: La Borracha (7), La Borracha (8), Cabecico del Tesoro (9), Camino del Pedregal (11), Cerro de los Santos (27), Cigarralejo (29), Los Cipreses (30), Miraflores (50), Molino de la Máquina (51), Molino de la Máquina (52). 


\section{LEVANTE:}

Región 1: Carraposa (19), Navarrés (53), Saitabi (87), Saitabi (88).

Región 6: La Abejuela (1), San Miguel de Liria (86), San Miguel de Liria (86b), San Miguel de Liria (86c), Los Villares (95)

Región 7: San Antonio de Calaceite (84), San Antonio de Calaceite (85), Tossal del Moro (92), Tossal del Moro (93), Tossal del Moro (94).

CATALUN̂A COSTERA:

Región 8: Can Butinya (12), Can Butinya (13), Can Butinya (14), Can Butinya (15), Can Butinya (16), Can Butinya (17), Can Vedell (18), Garrafols de Vallmoll (41), Manous (48), Mas Pullina (49), Penya del Moro (74), Penya del Moro (75), Penya del Moro (76), Penya del Moro (77), Puig Castellar (78), Rubi (81), Selva del Camp (89), Tarragona (C./Apodaca) (91).

Región 9: Las Corts (38), Las Corts (39).

\section{ARAGÓN:}

Región 11: Cabezo de la Guardia de Alcorisa (10), Castelillo de Alloza (20), Castelillo de Alloza (21), Castelillo de Alloza (22), Castelillo de Alloza (23), Castelillo de Alloza (24).

\section{MESETA SUR:}

Región 15: Cerrón de Illescas (28).

\section{DE LOS PIRINEOS AL EBRO:}

Región 10: La Fita (40), Guissona (43), Guissona (44), Jebut (45), La Pedrera (73), Roques de Sant Formatge (80).

\section{MESETA NORTE-ORIENTAL:}

Región 12 (Meseta Oriental): Aguilar de Anguita (2), Las Arribillas (3), Las Arribillas (4), Las Arribillas (5), Jebut (45), Langa de Duero (46), Langa de Duero (47), Numancia (54), Numancia (55), Numancia (56), Numancia (57), Numancia (58), Numancia (59), Numancia (60), Numancia (61), Numancia (62), Numancia (63), Numancia (64), Numancia (65), Numancia (66), Numancia (67).

Región 13 (curso alto del Ebro):

\section{MESETA NORTE-OCCIDENTAL:}

Región 12b: Cerro de la Virgen de Tormejón (25), Cerro de la Virgen de Tormejón (26), Coca (31), Coca (32), Coca (33), Coca (34), Cuesta del Mercado (39), Palenzuela (68), Palenzuela (69), Palenzuela (70), Palenzuela (71), Palenzuela (72), Rauda (79), Las Ruedas (82), Las Ruedas (83), Simancas (90). Región 13b:

AREA ABULENSE:

Región 14: Cogotas (35), Cogotas (36).

\section{LOS TIPOS}

Como se aprecia de la lectura del catálogo, la coroplastia con representaciones de équidos agrupa tipos diversos de objetos que deben analizarse por separado.

\section{ÍNDICE POR TIPOS:}

Entre paréntesis, tras el yacimiento, se indica el número de catálogo. Aparecen subrayadas aquellas piezas que por tipología pudieran no ser équidos, o que por cronología serían ya romanos o posteriores), 
Figuras exentas de équidos con arreos, manta o silla, alforjas o restos de jinete: Baza (6), La Borracha (7), Cabecico del Tesoro (9), Can Butinya (12), Can Butinya (13), Can Butinya (14), Cerro de los Santos (27), Cigarralejo (29), Los Cipreses (30),La Fita (40), Guissona (43), Guissona (44), Lebut (45) (¿con jinete?), Manous (48), Miraflores (50), Molino de la Máquina (51), Navarrés (53), Penya del Moro (74), S. Miguel deLiria (86), S. Miguel de Liria (86b), S. Miguel de Liria (86c), Saitabi (88), Selva del Camp (89).

Figuras exentas de équidos sin arreos: La Abejuela (1), Las Arribillas (3), Castelillo de Alloza (20), Coca (33), Coca (34), Las Corts (37), Las Corts (38), Gaspares (42), Langa de Duero (46), Langa de Duero (47), Mas Pullina (49), Molino de la Máquina (52), Numancia (54), Numancia (55), Numancia (62), Numancia (63), Numancia (64), Penya del Moro (76), Puig Castellar de Sta. Coloma de Gramanet (78), Roques de Sant Formatge (80), Saitabi (87), Tarragona (C. Apodaca) (91), Tossal del Moro (Pinyeres) (93), Tossal del Moro (Pinyeres) (94), Cerro Macareno (96).

Figuras exentas pero demasiado incompletas para decidir si llevaban arreos: Las Arribillas (5), La Borracha (8), Alcorisa (10), Camino del Pedregal (11), Carraposa (19), Garrafols de Vallmoll (41), Numancia (65), Las Ruedas (83), Simancas (90).

Figuras exentas de cuadrüpedos, pero quizá bóvidos u ovicaprinos: Las Arribillas (4), Can Butinya (15), Can Butinya (16), Can Butinya (17), Cerro de la Virgen de Tormejon (26), Coca (31), Coca (32), Numancia (66), Numancia (67), Penya del Moro (75), Penya del Moro (77). Los Villares (95)

Apliques de tapadera: Aguilar de Anguita (2).

Apliques de simpula: Numancia (57), Palenzuela (68), Palenzuela (69), Palenzuela (70), Palenzuela (71), Palenzuela (72), Rauda (79), Las Ruedas (82).

Otros apliques: Cogotas (35), Numancia (58).

Morillos (en casi todos los casos cabría discutir su carácter de équidos): Castelillo de Alloza (21), Castelillo de Alloza (22), Castelillo de Alloza (24), Cerro de la Virgen de Tormejón (25), Cogotas (36), La Pedrera (73), Rubi (81), S. Antonio de Calaceite (84), S. Antonio de Calaceite (85), Tossal del Moro (Pinyeres) (92).

Relieve: Cerrón de Illescas (28).

Planta Pedis: Numancia (60), Numancia (61).

Pico vertedor: Can Vedell (18), Numancia (56).

Objeto de función indeterminada: Numancia (59).

Animales que con seguridad no son équidos aunque a vèces se ban considerado como tales: Castelillo de Alloza (23), Cuesta del Mercado (39). 


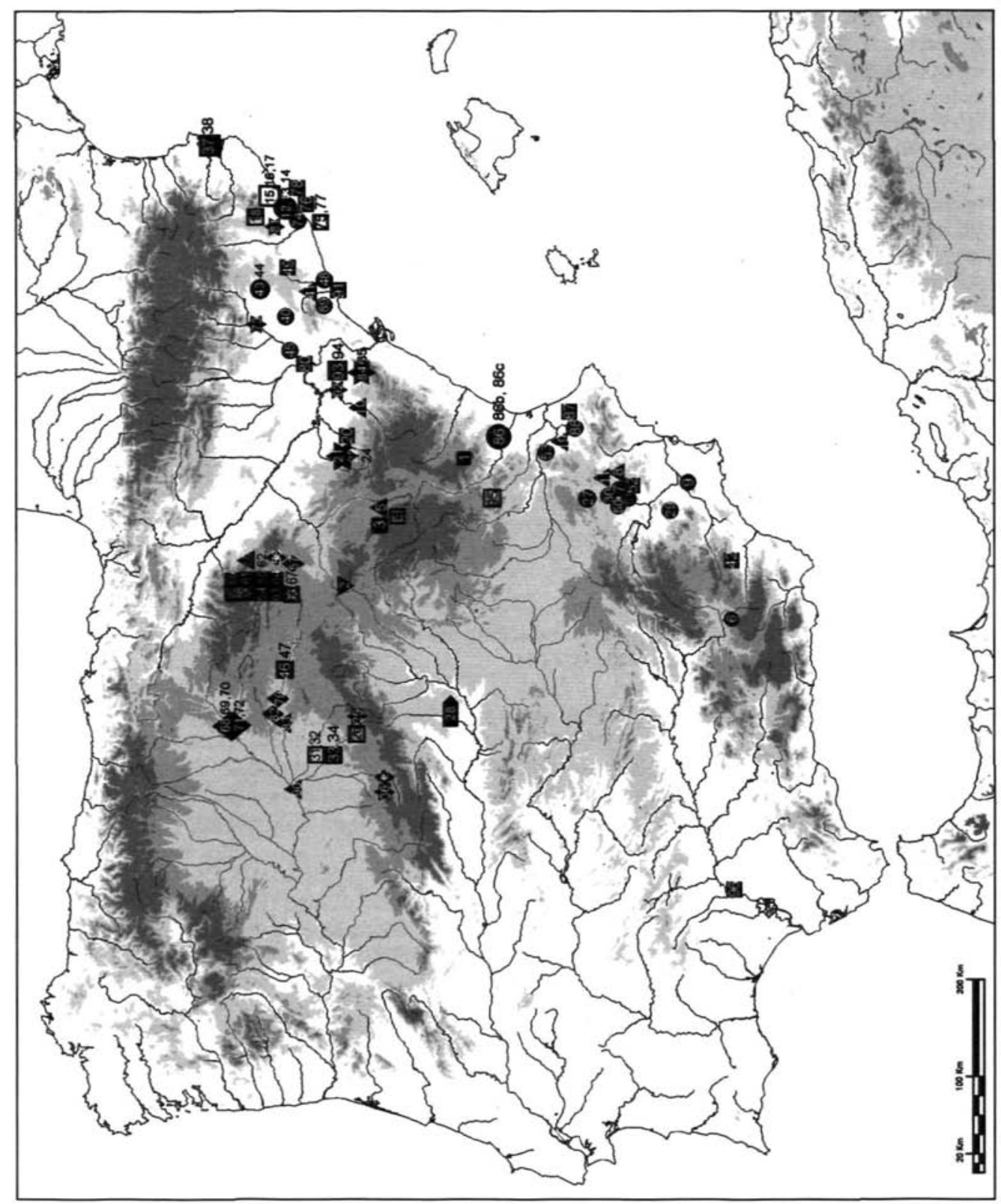

Figura 3: Distribución de hallazgos por tipos. Círculos rellenos: Figuras exentas de équidos con arreos. Cuadrados: Figuras exentas de équidos sin arreos. Triángulos: Figuras exentas de équidos incompletas. Cuadrados huecos: Cuadrúpedos dudosos, quizá no sean équidos. Triángulos invertidos: Apliques de tapadera. Rombos: Apliques de simpula. Rombos huecos: otros apliques. Estrellas: Morillos. Cartel: Relieve. Medios cuadrados: otros. El tamaño es proporcional al número de piezas. Los números remiten al catálogo. 
Con diferencia, la categoría más numerosa y extendida (Figura 3, círculos, cuadrados y triángulos rellenos) es la formada por figuritas exentas de équidos (normalmente no mayores de $12 \mathrm{~cm}$. de longitud máxima) modeladas a mano en arcilla bastante depurada y cocida. Estas piezas son 57 , incluyendo las piezas dudosas, y suponen un $57 \%$ del total.

Se distribuyen por toda el área de dispersión, pero con una diferencia quizá significativa. Las figuras exentas que presentan pintado algún tipo de arreo de monta (como riendas o cabezada), o manta o silla de montar (normalmente realizadas mediante apliques plásticos o pellizcando la arcilla), o toneles para transportar líquido, o incluso restos claros de haber llevado jinete, son todas ellas del área costera peninsular 'ibérica' (Fig. 3, círculos). Estas piezas suman 23 ejemplares (la mitad de los caballitos exentos, y un $23.5 \%$ del total.

\section{Piezas con jinete.}

Es posible los numerosos caballitos de Numancia (nos. $54 \mathrm{ss}$.), en el interior, tuvieran a menudo jinetes, pues se conocen varias figurillas masculinas independientes en barro que quizá pudieran acompañar a los caballos (e.g. Schulten 1914-31: Taf. 35; Wattenberg, 1963: Tabla XVII.462), aunque ello no es seguro. En el caso de las piezas ibéricas el jinete parece haberse modelado a menudo solidariamente con el caballo, con lo que quedan al menos parte de las piernas ( $n^{\circ} .48,86 c, 89$, quizá 45). De todas formas, estas figuras con jinete son muy escasas y nunca se ha conservado la pieza completa.

Piezas con manta. El problema de la silla.

Un segundo subgrupo es el de los caballos que parecen llevar manta o quizá silla de montar. Si se trata de una manta acolchada no hay en principio problema, pues conocemos sobradamente que la manta o ephippium de forma aproximadamente rectangular es el sistema habitual de monta del caballo ibérico, como ya demostrara sobradamente Cuadrado (1950:110 ss.). Si es una silla de armazón, sí que tenemos un problema, pues los iberos no la conocieron ${ }^{[6]}$.

La cuestión es, por un lado, que en la escultura mayor (como en el caballo de Casas de Juan Núñez en Albacete, en el segundo caballo de Porcuna, en el primero de Villares o en el cipo de Jumilla), en la menor (todos los exvotos con montura del Cigarralejo), o en la cerámica (La Alcudia) la manta es siempre rectangular, como por otro lado parece lógico ${ }^{[7]}$. Sin embargo, en las figurillas de barro encontramos sistemáticamente lo que parecen mantas curvas, inusitadas $\left(n^{\circ} 8,13,14,29,50,51\right)$.

Por otro lado, en algunos casos el relieve es tan acusado, y la parte colocada sobre la cruz es tan gruesa, que da claramente la sensación de que se ha representado una suer-

[6] Como tampoco el mundo griego, ver Anderson (1961:80-81). Lo que se empleó en el Mediterráneo antiguo es una manta con diversos tipos de acolchado para acomodar al jinete. La silla rígida parece de origen celta o asiático, y fue adoptada por los romanos, según los datos iconográficos, a comienzos del Alto Imperio. Sin embargo, ya aparece representada en el monumento cesariano de Sr Remy en Provenza como parte del equipo galo. Poco después es incluida en el repertorio iconográfico romano.

[7] También hay numerosos ejemplos de monta 'a pelo', incluso en escultura mayor, como el segundo jinete de Los Villares de Albacete 
te de silla de montar del tipo moderno llamado 'inglés', o incluso una silla con cuatro borrenes $\left(n^{\circ} 12,86,88\right)$; tal cosa no es posible en el mundo ibérico, que no conocía la silla de armazón.

En consecuencia, en los casos en que parece haber una manta curva nos encontramos ante una verdadera rareza; el ejemplo de la única figura de barro del Cigarralejo es paradigmático $\left(n^{\circ} 29\right)$; es la única pieza de barro, la única con ¿manta? curva, y se halló separada del resto del conjunto, en la ladera del cerro donde se ubica el santuario (véase Cuadrado, 1950: Fig. 15). Varias de las piezas procedentes de la zona de Jumilla en Murcia, publicadas por Hernández y Gil $(1999)\left(n^{\circ} 8,30,50,51\right)$ son casi con seguridad de tradición indígena pero de época romana, incluso del s. II d.C.; la del Cigarralejo, fuera de contexto (n²9), podría ser también de época romana imperial. Incluso las piezas catalanas de Can Butinya, con manta (?) curva $\left(\mathrm{n}^{\circ} 12,13,14\right)$ se hallaron en superficie y, aunque han sido asignadas a época ibérica, podrían incluso fecharse siglos después, en el s. II d.C. por el contexto de materiales de la zona. Por lo que se ve, no habría problema en desplazar a época imperial romana todas estas piezas con mantas curvas o quizá silla; pero con ello no haríamos sino desplazar también el problema, porque la silla romana es completamente diferente de esta especie de 'silla inglesa' flexible, contando con cuatro borrenes muy marcados y altos para asentar bien al jinete que no llevaba estribos, y un marco rígido de madera, todo lo cual se colocaba sobre una manta rectangular (e.g. Connolly, van Driel 1991; Dixon, Southern 1992:70 ss.; Junkelmann, 1990-1992).

Así pues, no sabemos realmente qué son estas piezas curvas sobre los caballos: pueden ser mantas -pero es raro que sólo aparezcan en la coroplastia, mientras que todas las demás manifestaciones llevan mantas rectangulares-; no pueden ser sillas iberas (que no existieron) o romanas altoimperiales; y difícilmente se pueden llevar todas estas piezas a época tardorromana. Podrían en último extremo ser sillas de tipo romano muy simplificadas, eliminando los cuatro borrenes, pero eso resulta una excusa más que una explicación.

Hay dos casos en que lo que tenemos es claramente una silla de montar (especialmente $n^{\circ} 86$-zona de Liria- y n 88 -zona de Saitabi-). En ambos casos coincide que no hay contexto arqueológico, y por la propia morfología de las piezas y la silla creemos estar ante unas piezas muy posteriores a época ibérica, probablemente modernas.

\section{Piezas con cabezada o arreos}

En tercer lugar, también parecen pertenecer exclusivamente a la fachada mediterránea las figuras con representación de arreos, bien pintados, o incisos o realizados mediante toscas aplicaciones plásticas.

Dentro del primer grupo una de las piezas más elaboradas es la cabecita de Baza en Granada $\left(n^{\circ} 6\right)$, aunque la pintura no refleja una cabezada funcional (carece de bocado y la muserola está incompleta).

La pieza de Los Cipreses ( $\mathrm{n}^{\circ} 30$ ), quizá ya de época romana, presenta petral inciso y una mal entendida pieza aplicada sobre la grupa. Quizá se haya querido también indicar mediante toscas incisiones una cincha. 
Más elaboradas son las cabecitas de Guissona $\left(n^{\circ} 43,44\right)$, que combinan pintura rojiza-amarronada para crines y parte de la cabezada con apliques plásticos para indicar las fáleras metálicas y otra parte de la cabezada. Este sistema se empleó también en otras piezas, como en una de S. Miguel de Lliria ( $\left.\mathrm{n}^{\circ} 86 \mathrm{~b}\right)$ o la Penya del Moro $\left(\mathrm{n}^{\circ} 74\right)$. Chocante es la pieza de Navarrés (Valencia) ( $\left.\mathrm{n}^{\circ} 53\right)$, con crines y posible petral pintado, y lo que parece una silla de borrenes modelada (v. supra). La de Saitabi $\left(n^{\circ} 87\right)$ está muy pintada pero los patrones geométricos no imitan arreos. Por fin, la pieza del Cerro de los Santos ( $\left.\mathrm{n}^{\circ} 27\right)$ es de terracota según Jiménez Navarro, pero por la técnica en que está realizada la cabezada, en relieve no aplicado, la pieza -que no hemos examinado directamente- debería estar hecha a molde.

\section{Acémilas}

Caso peculiar es el de la acémila cargada con dos grandes toneles cerámicos procedente de la necrópolis del Cabecico del Tesoro $\left(\mathrm{n}^{\circ}\right.$ 9), hallada en una tumba (la 578) sin apenas ajuar (restos de dos vasos cerámicos) y sin materiales fechables. En todo caso, documenta en un contexto francamente improbable (ajuar funerario) la faceta más humilde del empleo de los équidos, en este caso el transporte de materiales. No se aprecian restos de arreos pintados.

\section{Otros}

Aparte del amplio grupo de piezas incompletas en las que no es posible decidir si llevaban algún tipo de elementos de monta o no, e incluso del grupo de figuras en las que ni siquiera estamos seguro que nos encontremos ante équidos (podrían ser otros cuadrúpedos), hay toda otra serie de tipos, algunos de ellos muy característicos, y que en algunos casos se alejan claramente de las figurillas que venimos describiendo.

Uno de ellos es el ejemplar procedente de la necrópolis (?) de Aguilar de Anguita en Guadalajara $\left(n^{\circ} 2\right)$, en el que un caballito ejercía las funciones de asa de una tapadera. No podemos saber si muchos otros caballitos similares, del área ibérica pero también de la zona de Numancia, pudieron pertenecer a asas de este tipo. Además, el Marqués de Cerralbo considera, por unos agujeros en la tapa, que quizá originalmente hubiera una figura humana junto al caballo, lo que no está contrastado en ningún otro caso.

\section{Morillos}

Una categoría por completo diferente es la de las figuras de cuadrúpedos más o menos estilizadas que a menudo parecen representar caballos, pero en otros casos pueden ser otros animales, que aparecen perforadas y vienen siendo interpretadas como piezas laterales de morillos $^{[8]}$. No vamos ha realizar aquí un estudio específico de esta muestra particular de coroplastia. Sin embargo, nos llama la atención el que a menudo estas piezas estén decoradas con pintura (lo que tiene poco sentido dada su exposición al fuego) y rara vez aparecen quemadas. Su pasta además suele ser, contrariamente a lo que cabría esperar, muy depurada y compacta. Así, las piezas del Castelillo de Alloza (nos. 21, 22), y quizá

[8] La bibliografia relevante aparece en cada una de las piezas. En general, ver sobre todo Maluquer (1963) 
la del Tossal del Moro de Pinyeres ( $\mathrm{n}^{\circ}$ 94) tienen trazos pintados complejos que señalan la manta, cincha y petral.

Estos morillos aparecen sobre todo en la zona de la cuenca media-baja del Ebro (Figura 3), en zonas de fuerte tradición de Campos de Urnas, donde se conocen desde la I Edad del Hierro, y también muy ocasionalmente en la Meseta. En cambio están por completo ausentes en el mundo ibérico levantino y meridional, aunque hay ejemplares de morillos no zoomorfos en poblados ibéricos valencianos, por ejemplo.

Apliques de simpula $y$ de otros recipientes.

Sólo en la cuenca del Duero, y hasta ahora no al Este de Numancia, se da un tipo de aplique modelado a mano o a molde, representando prótomos de caballo, y que se coloca sobre recipientes. La categoría más homogénea son los apliques de cazos o simpula, documentados sobre todo en la necrópolis palentina de La Palenzuela, y bien estudiados por Martín Valls (1990), pero también conocidos en Numancia, Las Ruedas, Rauda y probablemente en otros puntos de la cuenca del Duero. En cambio, las piezas de Cogotas $\left(\mathrm{n}^{\circ}\right.$ 35) y Numancia ( $\left.n^{\circ} 58\right)$, aunque probablemente apliques, no pertenecen a cazos. De hecho la numantina pertenece al grupo de las llamadas 'trompas de guerra', como la de Simancas quizá ( ${ }^{\circ} 90$ ), y la de Cogotas, maciza, podría incluso pertenecer a un cuerpo de caballito perdido.

\section{Elementos de pico vertedor}

Una categoría relacionada con la anterior es la del escaso número de piezas que parecen picos vertedores de jarro, como el ejemplar de Numancia $\left(n^{\circ} 56\right)$ y probablemente el de Can Vedell en Barcelona ( $\left.\mathrm{n}^{\circ} 18\right)$.

Exvotos en forma de planta de pie con remate equino.

Sólo conocemos dos ejemplares de este tipo de exvoto, procedentes ambos de Numancia (nos 60-61), y son los únicos en los que la funcionalidad votiva parece asegurada.

\section{Relieve}

En una categoría por completo diferente a todas las anteriores, y en realidad un unicum conservado por azar, está el relieve del Cerrón de Illescas en Toledo ( $\left.{ }^{\circ} 28\right)$, imagen simbólica muy compleja de larga tradición mediterránea, probablemente conservada gracias a un incendio accidental. Ha sido bien estudiada por Balmaseda y Valiente, entre otros, y no procede hacer aquí mayores consideraciones.

\section{CRONOLOGÍA}

Existe en la bibliografía reciente una tendencia a atribuir la coroplastia con imágenes de caballos a una época muy avanzada de la Edad del Hierro ${ }^{[9]}$, hasta el punto de que en

[9] E.g. Galán Domingo (1989-90:183). 
ocasiones piezas halladas fuera de contexto se atribuyen al s. II o I a.C. sobre la base de esta tendencia generalizada. Y sin embargo, como nos muestra el catálogo y la Figura 4, la realidad no es exactamente así.

\section{ÍNDICE POR CRONOLOGÍA}

Con-cierta-seguridad ss. VI-IV a.C.: Aguilar de Anguita (2), Baza (6), La Pedrera (73), Penya del Moro S. Just Desvern (74), Penya del Moro S. Just Desvern (75), Penya del Moro St. Just Desvern (76), Penya del Moro St. Just Desvern (77), Roques de Sant Formatge (80), Tossal del Moro Pinyeres (93), Tossal del Moro de Pinyeres (94), Cerro Macareno (96).

Con-cierta-seguridad en los siglos III-I a.C.: Las Arribillas (3), Las Arribillas (4), Las Arribillas (5), Can Vedell (18), Castelillo de Alloza (20), Castelillo de Alloza (21), Castelillo de Alloza (22), Castelillo de Alloza (23), Cerro de la Virgen de Tormejon (25), Cerro de la Virgen de Tormejón (26), Cerrón de Illescas (28), Coca (31), Coca (32), Coca (33), Coca (34), Cogotas (35), Las Corts (37), Las Corts (38), Garrafols de Vallmoll (41), Guissona (43), Guissona (44), Manous (48), Numancia (54), Numancia (55), Numancia (56), Numancia (57), Numancia (58), Numancia (59), Numancia (60), Numancia (61), Numancia (62), Numancia (63), Numancia (64), Numancia (65), Numancia (66), Numancia (67), Palenzuela (68), Palenzuela (69), Palenzuela (70), Palenzuela (71), Palenzuela (72), Puig Castellar (78), Rauda (79), San Antonio de Calaceite (85), S. Miguel de Liria (86b), San Miguel de Liria (86c), Selva del Camp (89), Simancas (90), Tarragona (C. Apodaca) (91),

Probablemente anterior al cambio de Era sin más precisiones: Cabezo de la Guardia (10), Can Butinya (12), Can Butinya (13), Can Butinya (14), Can Butinya (15), Can Butinya (16), Can Butinya(17), Carraposa (19), Castelillo de Alloza (24), Cuesta del Mercado (39), Fita (40), Las Ruedas (82), Las Ruedas (83), San Antonio de Calaceite (84),

Probablemente en torno a o posterior al cambio de Era: La Borracha (7), La Borracha (8), Camino del Pedregal (11), Los Cipreses (30), Langa de Duero (47), Miraflores (50), Molino de la Máquina (51), Molino de la Máquina (52), Navarrés (53), San Miguel de Lliria (86), Saitabi (88),

Sin datos minimamente fiables: La Abejuela (1),Cabecico del Tesoro (9), Cerro de los Santos (27), Cigarralejo (29), Cogotas (36), Gaspares (42), Jebut (45), Langa de Duero (46), Mas Pullina (49), Rubi (81), Saitabi (87), Los Villares (95).

Como se aprecia, hay un buen número de piezas que se fechan con cierta seguridad en fechas antiguas de la Edad del Hierro. Así, en el área catalana se encuentran los ejemplos bien datados más antiguos, en particular en la Penya del Moro de Sant Just Desvern: allí hay dos piezas del s. VI a.C. (nos. 74 y 75), y otras dos de fines del V al s. IV a.C. (nos. 76 y 77). El Tossal del Moro de Pinyeres ha dado dos figuritas a mano del s. V a.C. (nos. 93 y 94). En Roques de Sant Formatge hay otra pieza datada por asociación estratigráfica a material ático en el s. IV a.C., al igual que el ejemplar de La Pedrera de Vallfogona, parte de un morillo que probablemente es un équido ( $\mathrm{n}^{\circ} 73$ ). La pieza de la tumba 27 de la necrópolis de Baza $\left(\mathrm{n}^{\circ} 6\right)$ se fecha también en el s. IV a.C. Finalmente, el caballito del Cerro Macareno ( $\left.n^{\circ} 96\right)$ procede del estrato 18 , que sus excavadores fechan en el s. VI a.C. Sin embargo, tenemos dudas de esta última datación por dos razones: la asociación a una espuela típica de los ss. III-I a.C. y la similitud del caballito del Macareno con una pieza del Castrejón de Capote que probablemente es algo o bastante posterior. 


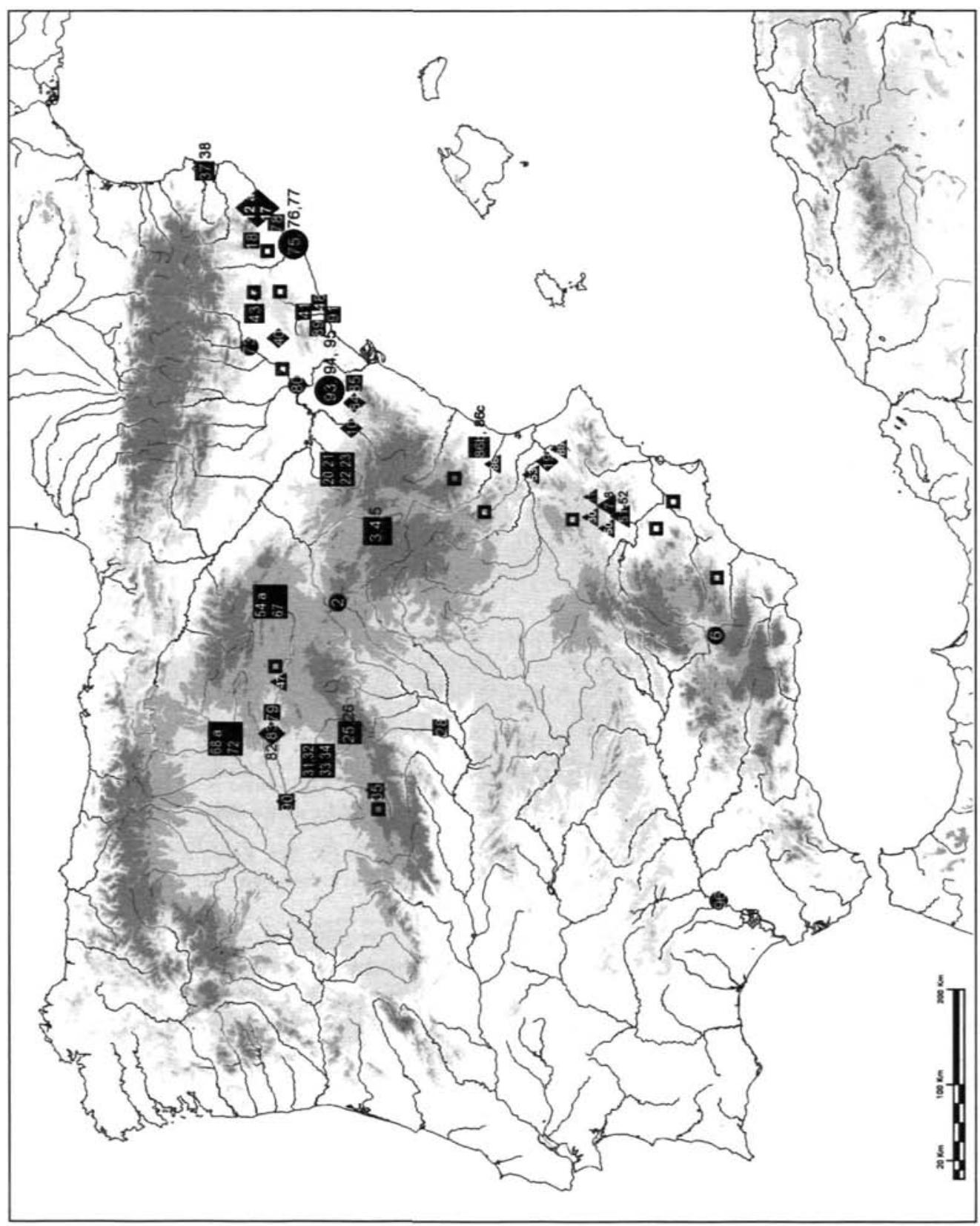

Figura 4: Distribución de hallazgos por cronología. Círculos: siglos VI-IV a.C. Cuadrados: siglos III-I a.C. Rombos: Probablemente anterior al cambio de Era (sin mayor precisión). Triángulo: Probablemente en torno a o posterior al cambio de Era. Cuadrado hueco: Sin datos fiables. 
En consecuencia, hay abundante documentación desde Cataluña a Andalucía de que la Cultura Ibérica producía figuritas de caballo desde el s. VI a.C. en adelante, y por tanto no hay razón para adjudicar arbitrariamente a Baja Época las piezas sin contexto, sesgando así la muestra.

Por lo que se refiera a la Meseta, el asa-tapadera de la necrópolis de Aguilar de Anguita, asociada a una urna de orejetas ibérica y otros elementos antiguos como un arma de frontón exento, puede atribuirse con cierta confianza a una fecha en torno al s. V a.C. Lo cierto es, que salvo esta excepción, el resto de la coroplastia celtibérica, vaccea y vetona, cuando tiene contexto, es tardío, del s. III a.C. en adelante, y quizá más tendiendo a las fechas más recientes de dicha horquilla. Coincidimos en ello con Lorrio (1997:247), entre otras cosas porque la tumba 'P' de Anguita es una de las más iberizantes del yacimiento, y la única prueba de una coroplastia verdaderamente antigua que está mucho mejor atestiguada en las zonas ibéricas.

De todos modos, lo cierto es que los datos muestran que el número de caballitos, tanto en la Meseta como en el área ibérica, aumenta a partir del s. III a.C., aunque la abundancia de ejemplos en Numancia y Palenzuela tiende a desequilibrar los porcentajes. En todo caso, hay todo un conjunto de yacimientos muy próximos a la moderna Jumilla, en Murcia (nos. 7, 8, 30, 50, 51, 52) que son probablemente ya de época romana altoimperial, aunque de clara tradición ibérica.

\section{CONTEXTO Y SIGNIFICADO}

Las piezas aquí recogidas se hallaron en una gran variedad de contextos. La inmensa mayoría proceden de poblados, y dentro de ellos no hay indicios especiales de que procedan de áreas interpretables como santuarios. Así, una pieza del Tossal de Liria procede de un Dpto. 'normal' (el 67), y nada indica que la pieza del Cerro Macareno ( ${ }^{\circ}$ 96) proceda de un santuario. Las tres figuras del Cerro Redondo de las Arribillas (nos. 3-5) proceden de contexto doméstico, al igual que las del Castelillo de Alloza (nos. 20 a 24). En la Meseta viene a ocurrir lo mismo: una de las piezas de Langa procede de un posible almacén de herramientas, la figura del Cerro de la Virgen de Tormejón ( $\left.n^{\circ} 26\right)$ procede de hábitat doméstico, y lo mismo parece ocurrir en Coca $\left(n^{\circ} 31\right.$ a 34) y Cogotas $\left(n^{\circ} 36\right)$.

Pero hay también figuras asociadas a contextos de probable significado cultual, como el gran conjunto hallado en superficie en Carraposa ( $\left.{ }^{\circ} 19\right)$, o las figuras halladas en el anejo del altar de Capote en Badajoz (s/n) o el depósito de Garvao (s/n). En cambio, no es seguro que la pieza de barro del Cigarralejo ( $\left.n^{\circ} 29\right)$ proceda del santuario, y lo mismo ocurre con la hallada en el Cerro de los Santos ( $\left.n^{\circ} 27\right)$.

Aparecen piezas también en los famosos silos catalanes, a veces sin contexto funerario, como parece ocurre en Can Vedell ( $\left.n^{\circ} 18\right)$, pero a veces en silos reutilizados como tumbas, como en Guissona (nos. 43-44).

Por fin, hay figuras de caballitos en necrópolis ibéricas como la Sep. 27 de Baza ( $\mathrm{n}^{\circ}$ 6) y la 577 del Cabecico del Tesoro ( $\left.n^{\circ} 9\right)$; y en otras celtibéricas como la tumba ' $P$ ' de Aguilar de Anguita ( $n^{\circ} 2$ ). Incluso en tumbas de filiación discutible, como la 77 de Les Corts 
en Ampurias (nos. 37 y 38). Caso aparte son los varios cazos hallados en la necrópolis de La Palenzuela (Palencia) (nos. 68 a 72).

En conjunto, las terracotas aquí catalogadas se pueden dividir en dos grandes grupos: el gran número de figurillas exentas, équidos per se, y otras en las que la imagen del caballo, como remate de un cazo, como extremo de un morillo, como aplique o pico vertedor, como remate de un exvoto, etc. complementa un objeto diferente ${ }^{[10]}$.

Por lo que se refiere a la primera categoría, creemos que se han debido proponer todas las alternativas de interpretación posibles: exvotos, juguetes, símbolos de prestigio, símbolos psicopompos colocados en los ajuares funerarios, etc. ${ }^{[11]}$. Hay en efecto argumentos para defender todas estas opciones, y otras más, dependiendo simplemente de la inclinación de cada investigador, de qué ejemplos de contexto escojamos, y de la calidad de las piezas empleadas como ejemplo. Pero lo cierto es que la misma variedad de contextos arqueológicos nos está dando la clave: un mismo objeto puede ser empleado como juguete, como exvoto, o como símbolo en el ajuar funerario. No es necesario que una casa del mundo antiguo tenga un altar para que haya en ella objetos de carácter religioso o ritual; pero a la inversa, no tenemos por qué interpretar todo objeto en una casa como ritual. Incluso dentro de una tumba, el ajuar no tiene un sólo significado: dentro de su variedad de objetos los hay puramente funerarios, propiedades queridas del difunto, juguetes en tumbas infantiles, símbolos de estatus o profesión, etc. El ajuar funerario no es monolítico y sus diversos objetos pueden pertenecer a categorías diferentes ${ }^{[12]}$. Y recurrir a 'paralelos' foráneos, celtas, romanos o griegos, no soluciona el problema, porque la misma situación se da en esas regiones. Es mucho mejor intentar explicar estas figuras extremadamente sencillas desde una óptica puramente interna.

En estas condiciones es perder el tiempo tratar de dotar de un significado único a todas las figuras de caballito: éste dependerá de su contexto arqueológico ${ }^{[131}$. Y no es des-

[10] Distinción práctica ya planteada, por cierto, por Genera (1988:225).

[11] A modo de muestra en absoluto exhaustiva: Almagro Basch (1953) y Balil (1955-50) insiste con paralelos griegos en el carácter votivo de las ofrendas de caballitos en las tumbas. El marqués de Cerralbo creía que su figurita de Aguilar de Anguita tendría un simbolismo solar (1911:48). J. Barrio (1999:246) se inclina para el mundo vacceo y veton, con cierta vaguedad, por un contexto no bien definido de la religiosidad doméstica, sin descartar su presencia en ámbitos votivos o funerarios. Incluso atribuye a los morillos con cabeza de caballo una asociación a los cultos domésticos. Galán Domingo (1989-90), refiriéndose al ámbito celtibérico, considera que los caballitos, e incluso los morillos, se asocian al ámbito infantil, aunque no descarta alternativas. Jiménez Navarro (1943) pensaba lógicamente que el caballito del Cerro de los Santos sería un exvoto, mientras que Cuadrado (1950) no estaba tan seguro para el ejemplar del Cigarralejo). Marco Simón (1989:117) parece inclinarse porque las figuritas de caballo sean exvotos, incluso en las de Numancia, y desde luego es explícito en considerar exvoto un caballito de Alloza (Marco 1984:91). J. Pérez Ballester, ante el hallazgo en superficie de un gran número de terracotas en lo alto del cerro de La Carraposa, identifica automática y tentativamente el lugar con un espacio sacro (1998:149). Lo mismo opinan el estudioso de las piezas sin contexto de Can Butinya (de la Pinta, 1983). J. Puche (1997:243) repasa las alternativas, parece inclinarse por una multifuncionalidad, para acabar inclinándose por la idea de Garcés de un significado religioso asociado a cultos domésticos. Taracena en su momento consideraba las piezas numantinas como 'ídolos' y exvotos (Taracena: 1925). Recientemente, Vilá duda entre las diversas alternativas, inclinándose finalmente por la interpretación en clave religiosa (1994).

[12] Fenómeno mejor conocido en el caso de Grecia. Ver Quesada (1991:77-81) con más referencias.

[13] Esta idea se va extendiendo (e.g. Genera 1988:226, tímidamente; Blanco, 2001 e.p.). 
cabellado que un objeto que ' $\mathrm{x}$ ' modelara con la mano como juguete de su retoño acabara en un depósito funerario tras la muerte del niño, o en un depósito votivo como agradecimiento por su recuperación de una enfermedad, o... las posibilidades son infinitas. Tratar de aplicar una categorización cerrada a los objetos polisémicos es poner puertas al campo, o encerrar la mente humana, con toda su flexibilidad, en las celdillas de una 'Tabla' de ordenador.

En cuanto a las otras categorías de piezas, cada una es un mundo en sí mismo. Las piezas en planta pedis, aún careciendo de contexto, son claramente votivas. Los simpula celtibéricos, asociados a patrones de comensalidad y a rituales de bebida, no son objetos rituales per se, pero la decoración de sus mangos remite a un mundo donde el caballo, como el banquete y el consumo social de alcohol son símbolos sociales muy poderosos. Los morillos siguen planteando a nuestro juicio serios problemas de funcionalidad e interpretación, y sería necesario volver sobre su posible significado en la Segunda Edad del Hierro.

\section{ADDENDUM}

En pruebas este artículo, se ha publicado el trabajo de R.M $M^{2} \operatorname{Loscos,} M^{2}$ R. Martínez y M.A Herrero "Resultados de la segunda campaña de excavación en el yacimiento ibérico El Cabo (andorra, Teruel), en Kalathos 18-19, 1999-2000, págs. 27-64. Se trata de un yacimiento ibérico fortificado antiguo, fechado en el s. V a.C., en el que ha aparecido una nueva figura de arcilla.

\section{Cat. 97}

EL CABO (1116). Teruel, reg. 10. TERRACOTA (BULTO R.) Figura exenta.

Contexto doméstico. Cabeza y cuello de caballo de arcilla cocida. La parte externa del cuello, la crin y el frente de la cabeza están decorados con pintura roja. Los ojos son perforaciones que atraviesan la cabeza.

Lg. $5 \mathrm{~cm}$. M. $s$ V a.C.

LOSCOS, MARTÍNEZ, HERRERO 1999-2000:42-43 y Fig. 15

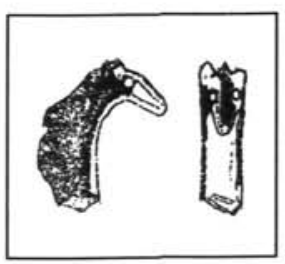




\section{BIBLIOGRAFIA}

ABAD CASAL, L. (1983): "Un conjunto de materiales de la Serreta de Alcoy". Lucentum 2, 173197.

AGUILERA Y GAMBOA, E., Marqués de Cerralbo (1911, inéd.): Páginas de la Historia Patria por mis excavaciones arqueológicas, 5 vols.

ALDANA NACHER, C. (1984): "Un nuevo exvoto ibérico procedente del cerro de San Miguel de Liria (Valencia)". Archivo de Arte Valenciano 65, 82-83.

ALMAGRO BASCH, M. (1953): Las necrópolis de Ampurias I. Introducción y necrópolis griegas. Monografias Ampuritanas III. Barcelona.

ALONSO HERNÁNDEZ, P.; BENITO LÓPEZ, J.E. (1991-92) "Figuras zoomorfas de barro de la Edad del Hierro en la Meseta Norte". Zepbyrus 44-45, 525-536.

ANDERSON, J.K. (1961): Ancient Greek Horsemanship. Berkeley.

ARTEAGA, O.; PADRÓ, J.; SANMARTí, E. (1990): El poblado ibèrico del Tossal del Moro de Pinyeres (Batea, Terra Alta, Tarragona). Monografies Arqueològiques del Institut de Prehistoria 7. Barcelona.

ATRIÁN JORDÁN, P. (1957): "Excavaciones en el poblado ibérico de El Castelillo (Alloza, Teruel). Primera Campaña". Teruel 17-18, 203-228.

ATRIÁN JORDÁN, P. (1959): "Excavaciones en el poblado ibérico de El Castelillo (Alloza, Teruel) 2a y 3a campañas" Teruel 22, 225-260.

ATRIÁN JORDÁN, P. (1966): "Excavaciones en el poblado ibérico de 'El Castelillo' (Alloza, Teruel). Cuarta y Quinta campañas". Teruel 36, 155-207.

ATRIÁN JORDÁN, P.; MARTINEZ, M. (1976) "Excavaciones en el poblado ibérico del Cabezo de la Guardia (Alcorisa, Teruel)". Teruel 55-56, 59-97.

BALIL, A. (1956): "Tres ejemplares de coroplástica ibérica en el Museo Arqueológico de Barcelona". Ampurias 17-18, 255-264.

BALMASEDA, L.J.; VALIENTE, S. (1979): "Excavaciones en el Cerron de Illescas". NAH 7, 153-210.

BALMASEDA, L.J.; VALIENTE, S. (1981): "El relieve de Illescas" AEspA 54, 215-238.

BARBERÁ FARRAS, J. (2000): El poblat ibèric de la Penya del Moro de Sant Just Desvern (Baix Llobregat). Les excavacions realitzades desde el 12 d'abril de 1972 fins al 31 dessembre de 1990. s.1.

BARBERÁ FARRÁS, J.; SANMARTÍ, E. (1982): Excavacions al poblat ibèric de la Penya del Moro de Sant Just Desvern (Barcelona). Campanyes 1974-1975 $i$ 1977-1981. Monografias Arqueológicas de la Diputación Barcelona 1. Barcelona.

BARRIO MARTÍN, J. (1994): "Las manifestaciones plásticas entre los pueblos de cultura celtibérica en las tierras de Segovia". Estudios Segovianos 35, 397-427.

BARRIO MARTÍN, J. (1999): La II Edad del Hierro en Segovia (España): estudio arqueológico del territorio y la cultura material de los pueblos prerromanos. BAR IS 790. Oxford.

BEIRAO, C. de M. et alii (1985) "Depósito votivo da II Idade do Ferro de Garvao. Noticia da primeira campanha de escavaçoes". O Arqueólogo Português IV,3, pp. 45-136. 
BERROCAL RANGEL, L. (1992): Los pueblos célticos del Suroeste de la Península Ibérica. Madrid. BERROCAL RANGEL, L. (1994): El altar prerromano de Capote. Ensayo etnoárqueológico de un ritual céltico en el Suroeste peninsular. Madrid.

BLANCO GARCÍA, J.F. (1986): Coca Arqueológica. Segovia

BLANCO GARCíA, J.F. (1994): "El castro protohistórico de la Cuesta del Mercado (Coca, Segovia)". CUPAUAM 21, 35-80.

BLANCO GARCÍA, J.F. (2001 e.p.): "En torno a la iconografía del caballo entre los pueblos prerromanos del centro-norte de la Península Ibérica". F. Quesada, M. Zamora (eds.) El caballo en la Antigua Iberia. Madrid.

Van BOEKEL, G. M.E.C. (1989): "Roman terracotta horse figurines as a source for the reconstruction of harnessing". C. Van Driel Murray (ed.) Roman Military Equipment. BAR IS 476, 75121. Oxford.

BONET ROSADO, H. (1995): El Tossal de Sant Miquel de Lliria. Valencia.

CABRÉ AGUILÓ, J. (1983-84): "San Antonio de Calaceite. (Catálogo Monumental de Teruel. Tomo 1)". Kalathos 3-4, 9-49.

CASTRO GARCÍA, L. (1971): La necrópolis de Pallantia. Palencia.

COLOMINAS ROCA, J. (1941): "El poblado ibérico de Guissona (Lérida)". Ampurias 3, 35-38.

CONNOLLY, P.; van DRIEL MURRAY, C. (1991): "The Roman cavalry saddle". Britannia 22, 3350.

CUADRADO DIAZ, E. (1950): Excavaciones en el santuario ibérico del Cigarralejo (Mula, Murcia). Informes y Memorias 21. Madrid.

CHOCOMELI GALÁN (1951): "Nuevos ejemplares de plástica ibérica". Saitabi 1, 6-9.

DIXON, K.R.; SOUTHERN, P. (1992): The Roman cavalry. London.

EXCAVACIONES... (1912): Excavaciones de Numancia. Memoria presentada al Ministerio de Instrucción Pública y Bellas Artes por la Comisión Ejecutiva. Madrid.

FERNÁNDEZ MIRANDA, M.; OLMOS ROMERA, R. (1986): Las ruedas de Toya y el origen del carro en la Península Ibérica. Monografías del M.A.N. 9. Madrid.

FERRER SOLER, A.; GIRO, P. (1943): "La colección prehistórica de Museo de Villafranca." Ampurias 5, 200-210.

GALÁN DOMINGO, E. (1989-90): "Naturaleza y cultura en el mundo celtibérico". Kalathos 9-10, 175-204.

GARCÉS ESTALLO, I. (1991): Assimilació, resistència i canvi a la romanització en el mon ilenget. Tesis Doctoral inédita. Estudi General de Lleida. Lérida.

GARCÍA GUIRAO, J.D. (1977): "Dos nuevas terracotas". BAEAA 7, 74-75.

GENERA MONELLS, M. (1988): "Arts plastiques d'època ibèrica a Catalunya: les terracottes". Prehistòria i Arqueología de la conca del Segre, CLAP 7, 215-226.

HERNÁNDEZ CARRIÓN, E.; GIL GONZÁLEZ, F. (1999): "La colección de terracotas de équidos del museo Municipal 'Jerónimo Molina' de Jumilla (Murcia)". XXIV CNA Cartagena 1997, 367-375. Cartagena.

HERNÁNDEZ YLLAN, M. (1983): El yacimiento ibérico de Can Badell. Bigues-Riells del Fay (Vallés Oriental). Barcelona. 
JIMÉNEZ NAVARRO, E. (1943): "Figuras animalistas del Cerro de los Santos". Ampurias 5, 95-108. JUNKELMANN, M. (1990-92): Die Reiter Roms. I-III. Frankfurt.

JUNYENT SÁNCHEZ, E. (1973): "El primer corte estratigráfico realizado en Roques de Sant Formatge (Serós, Lérida) y algunas cuestiones en torno a la formación de la cultura ilergeta". NAH 2, 287-385. Madrid.

MALUQUER DE MOTES, J. (1963): "Sobre el uso de morillos durante la Edad del Hierro en la Cuenca del Ebro". Príncipe de Viana 24, 29-39.

MALUQUER DE MOTES, J.; MUÑOZ AMILIBIA, A.M.; BLASCO, F. (1960): "Cata estratigráfica en el poblado de La Pedrera (Vallfogona de Balaguer, Lérida)" Instituto de Arqueología y Prebistoria de la Universidad de Barcelona. Barcelona.

MARCO SIMÓN, F. (1984): "Consideraciones sobre la religiosidad ibérica en el ámbito turolense". Kalathos 3-4, 71-93.

MARCO SIMÓN, F. (1989): "Lengua, instituciones y religión de los Celtíberos". C. Blasco et al. Los Celtas en el Valle Medio del Ebro, 99-129. Zaragoza.

MARTÍN TOBÍAS, R. (1960-61): "Dos ejemplares de coroplastia ibérica hallados en Guissona (Lérida)". Ampurias 22-23, 294-296.

MARTín VALLS, R. (1990): "Los 'simpula' celtibéricos". BSAA 56, 144-169.

MATA PARREÑO, C. (1991): Los Villares (Caudete de las Fuentes, Valencia). Origen y evolución de la Cultura Ibérica. SIP TV 88. Valencia.

MONTESINOS MARTINEZ, J. (1982) “Arqueología ibérica a la comarca de la Costera". La Bastida de Les Alcuses. Moixent, 65-91.

OLLÉ, A.; OTIÑA, P.; VALLVERDU, J. (1997-98): "Una terracota ibèrica procedent de la Selva del Camp (Baix Camp)". Butlletí Arqueològic de la Reial Societat Arqueològica Tarraconense 1920, 27-40.

ORTEGO Y FRIAS, T. (1945-46): "El poblado ibérico del Castelillo de Alloza (Teruel)" Ampurias 7-8, 185-202.

OTIN̂A HERMOSO, P. (1998): "Els Ibers al camp de Tarragona". Kese 26, 8-13.

OTIÑA HERMOSO, P. (1999): "Terracotas ibéricas de Puig Castellar y Can Butinyà". Agora 4, 101117.

PALLARÉS SALVADOR, F. (1965): El poblado ibérico de S. Antonio de Calaceite. BordigheraBărcelona.

PELlicer CATALAN, M.; ESCACENA, J.L.; BENDALA, M. (1983): El Cerro Macareno. Excavaciones arqueológicas en España 124. Madrid.

PÉREZ BALLESTER, J.; BORREDA, R. (1998): "El poblamiento ibérico del Valle del Canyoles. Avance sobre un proyecto de evolución del paisaje en la comarca de La Costera (Valencia)". Saguntum 31, 133-152.

PÉREZ GONZÁLEZ, C.; BLANCO GARCÍA, J.F. (2000): "Nuevas investigaciones arqueológicas en Cauca". Revista de Arqueología 228, 38-47. Madrid.

PINTA RODRIGUEZ, J.L. de la (1983): "La col-lecció arqueológica de Can Butinyà (Badalona): figuretes i exemplars de coroplastia". Informació Arqueológica 41, 163-168.

PLA BALLESTER, E. (1956): "Un caballito ibérico, en cerámica, de Navarrés (Valencia)". Libro Homenaje al Conde de la Vega Sella, 285-291. Oviedo. 
PRESEDO VELO, F. (1982): La necrópolis de Baza. EAE 119. Madrid.

PUCHE, J. M. (1997): "Sobre un conjunt amb ceràmica calena decorada i terracotes trobat a Tarragona. Un posśible lloc de culte a la Tarraco republicana". Revista d'Arqueología de Ponent 7, 237-247.

QUESADA SANZ, F. (1991): "Muerte y ritual funerario en la Greica Antigua: una introducción a los aspectos arqueológicos". Arqueología de la Muerte. Cursos Fons Mellaria 1990. D. Vaquerico (ed.). Córdoba, 39-114.

QUESADA SANZ, F. (1997): El armamento ibérico. Estudio tipológico, geográfico, funcional, social y simbólico de las armas en la Cultura Ibérica (siglos VI-I a.C.). Monographies Instrumentum 3. Montagnac.

QUESADA SANZ, F. (2000): “Caballos, héroes y dioses en la Bética antigua”. Jornadas Ecuestres 2000 años de nuestro caballo. Sevilla, 67-100.

SACRISTÁN DE LAMA, J.D. (1986): "Consideraciones sobre el celtiberismo inicial en la cuenca media del Duero". BSAA 52, 205-213.

SACRISTÁN DE LAMA, J.D. (1986): La Edad del Hierro en el Valle Medio del Duero, Rauda (Roa, Burgos). Valladolid.

SÁNCHEZ MORENO, E. (1995-96): "El caballo entre los pueblos prerromanos de la Meseta Occidental". Studia Historica, Historia Antigua 13-14, 207-229.

SANZ MÍNGUEZ, C. (1998): Los Vacceos: cultura y ritos funerarios de un pueblo prerromano del valle medio del Duero. Arqueología en Castilla y León. Memorias 6. Salamanca.

SCHULTEN, A. (1914-1931): Numantia. Die Ergebnisse der Ausgrabungen 1905-1912. I-IV. München.

TARACENA AGUIRRE, B. (1925): "Arte Ibérico. Los vasos y las figuras de barro de Numancia". IPEK 75-93. Madrid.

TARACENA AGUIRRE, B. (1928): "Excavaciones en las provincias de Soria y Logroño". MJSEA 103. Madrid.

TARACENA AGUIRRE, B. (1941): Carta Arqueológica de España. Soria.

VILASECA DE PALLEJA, LL. (1968): "Valmoll". Ampurias 30, 362-364.

VILÁ, M. del V. (1994): "Figura zoomorfa de Montbarbat". Pyrenae 25, 141-149.

WATTENBERG SAMPERE, F. (1978): Estratigrafia de los cenizales de Simancas. Monografias del Museo Arqueológico de Valladolid 2. Valladolid.

WATTENBERG SANPERE, F. (1963): Las cerámicas indígenas de Numancia. BPH IV. Madrid. 